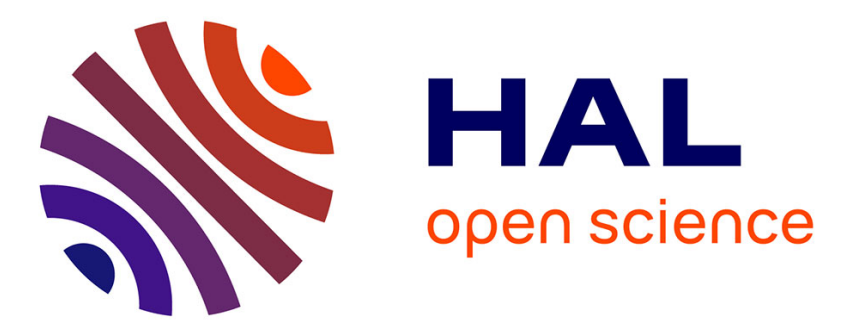

\title{
Hydroxylated hyperbranched polyesters as crosslinking agents for polyurethane networks: Partial modification of the $\mathrm{OH}$ chain ends
}

Damien Thomasson, Fernande Boisson, Emmanuel Girard-Reydet, Françoise Méchin

\section{To cite this version:}

Damien Thomasson, Fernande Boisson, Emmanuel Girard-Reydet, Françoise Méchin. Hydroxylated hyperbranched polyesters as crosslinking agents for polyurethane networks: Partial modification of the $\mathrm{OH}$ chain ends. Reactive and Functional Polymers, 2006, 66 (12), pp.1462-1481. 10.1016/j.reactfunctpolym.2006.04.012 . hal-02045868

\author{
HAL Id: hal-02045868 \\ https://hal.science/hal-02045868
}

Submitted on 13 Mar 2019

HAL is a multi-disciplinary open access archive for the deposit and dissemination of scientific research documents, whether they are published or not. The documents may come from teaching and research institutions in France or abroad, or from public or private research centers.
L'archive ouverte pluridisciplinaire HAL, est destinée au dépôt et à la diffusion de documents scientifiques de niveau recherche, publiés ou non, émanant des établissements d'enseignement et de recherche français ou étrangers, des laboratoires publics ou privés. 


\title{
HYDROXYLATED HYPERBRANCHED POLYESTERS AS CROSSLINKING AGENTS FOR POLYURETHANE NETWORKS: PARTIAL MODIFICATION OF THE OH CHAIN ENDS
}

\author{
Damien THOMASSON ${ }^{1) a)}$, Fernande BOISSON ${ }^{2)}$, Emmanuel GIRARD-REYDET ${ }^{1) b)}$, \\ Françoise MECHIN ${ }^{1)_{*}}$ \\ 1) Ingénierie des Matériaux Polymères-IMP, UMR CNRS \#5627, \\ Laboratoire des Matériaux Macromoléculaires, INSA de Lyon, Bât. Jules Verne, \\ 20, avenue Albert Einstein, 69621 Villeurbanne Cedex, France \\ 2) Service de $R M N$ de la FR $n^{\circ} 2151, B P 24$ \\ 69390 Vernaison, France
}

Published in Reactive \& Functional Polymers vol. 66, 1462-1481 (2006)

a) present address: CTE / PE2 / CC - Renforcement - 23 Place des Carmes Déchaux 63040 Clermont-Ferrand Cedex 9 - France

b) present address: CNRS Délégation Provence - 31 chemin Joseph Aiguier 13402 MARSEILLE Cedex 20 - France

corresponding author: $\quad$ Françoise MECHIN

fmechin@insa-lyon.fr

tel. : 33.4.72.43.85.48

fax: 33.4 .72 .43 .85 .27 


\title{
HYDROXYLATED HYPERBRANCHED POLYESTERS AS CROSSLINKING AGENTS FOR POLYURETHANE NETWORKS: PARTIAL MODIFICATION OF THE OH CHAIN ENDS
}

\author{
Damien THOMASSON ${ }^{1) a)}$, Fernande BOISSON ${ }^{2)}$, Emmanuel GIRARD-REYDET ${ }^{1) b)}$, \\ Françoise MECHIN ${ }^{1}{ }^{*}$ \\ 1) Ingénierie des Matériaux Polymères-IMP, UMR CNRS \#5627, \\ Laboratoire des Matériaux Macromoléculaires, INSA de Lyon, Bât. Jules Verne, \\ 20, avenue Albert Einstein, 69621 Villeurbanne Cedex, France \\ 2) Service de $R M N$ de la $F R n^{\circ} 2151, B P 24$ \\ 69390 Vernaison, France
}

\begin{abstract}
A $4^{\text {th }}$ generation commercial hyperbranched polyester (HBP) based on bis(hydroxymethyl) propionic acid, bis(MPA), was used as an original crosslinker for polyurethane networks. However a partial modification of the numerous hydroxyl groups was necessary to obtain complete miscibility between the three polyurethane precursors, i.e. macrodiol, diisocyanate and hyperbranched, HB, crosslinking agent. A monofunctional aromatic isocyanate, para-tolylisocyanate, pTI, was used for that purpose. The pristine hyperbranched polyester was at first quite fully characterized, especially concerning the initial distribution of hydroxyl groups between linear, L, and terminal, T, bis(MPA) units. ${ }^{1} \mathrm{H}$ and ${ }^{13} \mathrm{C}$ NMR (both for urethane formation and hydroxyl comsumption) and chemical titration were then used and compared for the determination of $\mathrm{OH}$ conversion. It appeared that a small part of the modifier was systematically lost in a side reaction with moisture, even though the reactive species had been thoroughly dried. All the remaining pTI molecules produced exclusively urethane end groups. NMR also demonstrated that the hydroxyls born by linear units had a lower reactivity as compared to T-type $\mathrm{OH}$ groups. Therefore their
\end{abstract}


relative proportion increases with the modification degree, and more and more modified crosslinkers become less and less reactive.

Calorimetric studies performed on pristine and partially modified HB polyesters revealed that hydrogen bonds played an important role as far as thermal behavior was concerned. With increasing modification, $\mathrm{Tg}$ increases but also ordered domains resulting from strong interactions between hydroxyl groups are progressively replaced by new structures created by self-assembling aromatic urethanes. The latter are responsible for a high-temperature pseudomelting for highly modified samples. However most of these interactions seem to remain intramolecular since the newtonian behavior of pristine HBP is maintained up to about 110$120^{\circ} \mathrm{C}$ for pTI-modified oligomers; but annealing at higher temperature can result in even more ordering and in a final loss of the newtonian behavior.

Keywords: hyperbranched polyesters; chemical modification; modification degree; urethane; hydrogen bonds 


\section{Introduction}

Macromolecules with a compact architecture can be of great interest as additives or as building blocks in novel polymeric materials. Among them, hyperbranched polymers represent an important part of the family of dendritic and multibranched polymers ${ }^{[1,2]}$. While dendrimers have perfect, monodisperse structures built around a core moiety with a branching point in every repeating unit, hyperbranched polymers are polydisperse and include some linear units in their molecular structure. However, these differences are not large enough to suppress some of their typical dendritic polymer characteristics. Similarly to dendrimers, hyperbranched polymers were shown to exhibit much lower solution viscosities than linear polymers due to the lack of entanglements and to their very low intrinsic viscosities, which result from their packed structure ${ }^{[3-6]}$. They also often possess very high solubilities compared to those of linear polymers, as a result of the large number of peripheral terminal functional groups available per macromolecule. These attractive properties allow to blend large amounts of hyperbranched polymers with thermoplastics ${ }^{[7-10]}$, but also with thermosetting precursors ${ }^{[11-13]}$ without increasing too much their viscosity, and even sometimes lowering it.

The properties of hyperbranched polymers in blends are indeed strongly determined by the nature of their terminal groups ${ }^{[14-17]}$. For example solubility, which mainly depends on endgroup structure, may be regulated by the partial or total chemical modification of the "terminal" groups. Due to the irregularities of hyperbranched polymers in their molecular architecture, these functional groups can be located not only in the periphery, as in perfect dendrimers, but also inside the globular branched structure; even the terminal functional groups of dendritic macromolecules can fold back to the inside ${ }^{[18]}$. Nevertheless, several authors could show that nearly all functional groups were accessible for small reagents ${ }^{[19,20]}$, which easily allows a quite total modification of functionalized hyperbranched polymers. 
Some hyperbranched oligomers and polymers are now commercially available on a large scale and among them, hydroxylated hyperbranched polyesters based on bis(methylol)propionic acid, bis(MPA), have been the subject of numerous studies dealing either with their synthesis ${ }^{[21-25]}$ or their characterization ${ }^{[26-29]}$. Their relatively well-known structure, together with their medium to high hydroxyl functionality, could make them good candidates as original precursors for new polymer materials. Our group has been working for many years on the synthesis of segmented polyurethanes and of polyurethane or polyurethane acrylate networks ${ }^{[30-32]}$, most of which are obtained from the reaction of hydroxylated compounds with diisocyanate-terminated prepolymers based on a macrodiol and excess diisocyanate ${ }^{[32-34]}$. Therefore the use of the above hyperbranched polyesters as specific crosslinking agents for such materials seemed to us a very promising way of synthesizing new polyurethane networks with a controlled architecture, as described in Figure 1. For such a purpose, the hyperbranched units obviously have at first to be miscible in bulk with the other precursors, namely the macrodiol and the diisocyanate. Unfortunately this is not the case for most macrodiols ( $\alpha, \omega$-dihydroxy polyesters, polyethers, polyolefines...), nor for commonly used diisocyanates. Consequently, a partial endcapping of the hydroxyl groups of the hyperbranched component by a monofunctional aromatic isocyanate was implemented with the aim of achieving crosslinking agents with tunable functionalities and miscibilities. 


\section{Experimental}

- reagents

A commercial fourth-generation hyperbranched hydroxy-functional polyester based on bis(methylol)propionic acid, bis(MPA) (Boltorn H40, HB40, Perstorp AB) and on a tetrafunctional core (pentaethoxylated pentaerythritol) was used without purification throughout this study. To illustrate the possible defects in the molecule architecture, a typical chemical structure of a lower "generation" is shown in Figure 2. As modifier and titrating agent, respectively, p-tolyl isocyanate (pTI) and p-toluenesulfonyl isocyanate (tosyl isocyanate, TOS), both from Aldrich, were used as received, as well as di- $n$-butylamine (Fluka) and the solvent, anhydrous THF (water $<0.02 \%$ ) from SDS.

\section{- OH modification reaction}

HB40 is not miscible with pTI, and therefore the chemical modification of the $\mathrm{OH}$ groups was carried out in solution. HB40 was at first carefully dried, then dissolved in anhydrous THF (concentration: $0.5 \mathrm{~g} / \mathrm{mL}$ ). The desired amount of pTI was then added and the mixture was allowed to react under argon at room temperature; no catalyst was used in order not to perturb the future syntheses of polyurethane networks. The reaction was run until total disappearance of the isocyanate peak $\left(2270 \mathrm{~cm}^{-1}\right)$ using FTIR spectrometry. The modified product was then recovered by THF evaporation (precipitation in a non-solvent was avoided, since it inevitably would have led to a partition between smaller and larger HB molecules), and thorough drying. The resulting samples were named after their actually measured modification degree (i.e. HBpTI19 refers to HB40, modified by pTI using an initial ratio $\mathrm{NCO} / \mathrm{OH}=0.25$, and for which $19 \%$ of the $\mathrm{OH}$ groups were finally found to be turned into urethane groups). 


\section{- OH titration}

A general procedure was established for the chemical determination of $\mathrm{OH}$ functions for crude and modified HB polyesters. It consisted in a titration by a strongly reactive isocyanate (TOS), followed by neutralization of the excess isocyanate by an aliphatic amine and backtitration with hydrochloric acid. In a first stage, the samples were thoroughly dried under a vacuum, and then dissolved in anhydrous THF $\left(\sim 0.5 \mathrm{~mol}_{\mathrm{OH}} / \mathrm{L}\right)$. After that, the same volume of a $1 \mathrm{~N}$ solution of TOS in THF was added and the mixture was reacted for $2 \mathrm{~h}$. Another same volume of a $2 \mathrm{~N}$ solution of di- $n$-butylamine was then added and the mixture reacted for 1 more hour. After diluting with acetone (co-solvent), the excess amine was finally back-titrated by a $1 \mathrm{~N} \mathrm{HCl}$ aqueous solution. The hydroxyl number was obtained with respect to the titration of a blank solution.

- physico-chemical analysis

$-{ }^{1} \mathrm{H}$ and ${ }^{13} \mathrm{C}$ NMR were used to determine the average modification degree $(\mathrm{OH}$ conversion, $\mathrm{t}_{\mathrm{m}}$ ) and the microstructure of the HB polymers. Spectra were recorded in DMSO-d6 with a 5 mm-QNP probe at $67^{\circ} \mathrm{C}$ on a Bruker DRX 400 spectrometer operating at $400 \mathrm{MHz}$ for ${ }^{1} \mathrm{H}$ and 100.6 $\mathrm{MHz}$ for ${ }^{13} \mathrm{C}$. Inversegate (ig) decoupling proton was used under appropriate conditions $\left(70^{\circ} \mathrm{rf}\right.$ pulse; $11.4 \mathrm{~s}$ recycle time) to obtain accurate relative values for the integrations of all carbon peaks.

- Differential Scanning Calorimetry (DSC) analysis of the samples was carried out on $\sim 10 \mathrm{mg}$ samples in aluminum pans, using a Mettler DSC30 apparatus. The heating rate was $10^{\circ} \mathrm{C} / \mathrm{min}$ under argon atmosphere. Thermogravimetric analysis, TGA, was run under the same conditions (but the atmosphere: nitrogen or helium) on a TGA2950 apparatus from TA Instruments.

- Rheological measurements were carried out with the help of a RDA II spectrometer (Rheometrics). Samples (1-1.5 mm-thick) were placed between parallel circular plates 
(diameter: $50 \mathrm{~mm}$ ). For thermomechanical measurements, the strain was set at $1.5 \%$ and the heating rate at $3^{\circ} \mathrm{C} / \mathrm{min}(\omega=1,10$ or $100 \mathrm{rad} / \mathrm{s})$. Isothermal rheological analysis was run at $110^{\circ} \mathrm{C}$ with a $10 \%$ strain, i.e. in the linear domain for all the samples.

- Finally, Wide-Angle X-ray diffraction (WAXS) measurements were performed on a Siemens D500 diffractometer with a Brentano-Bragg geometry $(40 \mathrm{kV}, 30 \mathrm{~mA}, \lambda=1.54 \AA)$, at room temperature.

\section{Results and discussion}

\section{Characterization of the microstructure of the initial HB4O}

Commercial HB polyesters from Perstorp have already been used in several studies for which they were quite completely characterized, especially recently by Žagar et al. ${ }^{[26-29]}$. However some of these measurements were carried out once again in this work to have a better insight of the specific lot used in this study, but most of all for comparison purposes (between crude and modified samples). A good knowledge of the chemical microstructure of the HB polyester was indeed particularly important in order to understand how it could be influenced by its chemical modification afterwards. Therefore the pristine HB40 was at first fully characterized by ${ }^{1} \mathrm{H}$ and ${ }^{13} \mathrm{C}$ NMR. Both spectra shown in Figure 3 are in good agreement with the structure depicted in Figure 2 as well as with former analyses of bis(MPA)-based HB polyesters ${ }^{[21]}$. Dendritic, D, linear, L and terminal, $\mathrm{T}$ units can be distinguished both by ${ }^{1} \mathrm{H}$ NMR using the methyl signal at 1.0-1.4 ppm and by ${ }^{13} \mathrm{C}$ NMR using either the carbonyl peaks [171-175 ppm], or that of the quaternary carbons, Cq, [45-51 ppm]. In the case of ${ }^{1} \mathrm{H}$ NMR, trifluoroacetic acid, TFA, can also be added in order to isolate the broad peaks associated with labile protons ( $\mathrm{OH}$ groups, but also residual water $\left.{ }^{[27]}\right)$. These 3 particular areas of the NMR spectra are presented in Figure 4. Using appropriate conditions (see experimental section), it is possible to compare quantitatively the relative areas of $\mathrm{C}=\mathrm{O}$ 
and $\mathrm{Cq}$-peaks with each other. For the relative proportions of $\mathrm{D}, \mathrm{L}$ and $\mathrm{T}$ units, comparable values from the 3 types of data are indeed obtained, as summarized in Table 1. Numerous linear units are detected, meaning that HB40 bears about $48 \%$ terminal $\mathrm{OHs}$ and $52 \%$ linear OHs. From these data, it is possible to estimate a degree of branching, DB, using the definitions given either by Frechet:

$$
\mathrm{DB}_{\text {Frechet }}=\frac{\mathrm{D}+\mathrm{T}}{\mathrm{D}+\mathrm{L}+\mathrm{T}}
$$

or Frey:

$$
\mathrm{DB}_{\text {Frey }}=\frac{2 \mathrm{D}}{2 \mathrm{D}+\mathrm{L}}
$$

Both series of values are reported in Table 1. The main difference lies in the fact that $\mathrm{DB}_{\text {Frechet }}$ takes into account the linear propagation as a branching direction and thus overestimates DB for small molecules, whereas both definitions merge for higher molar masses. Here average values of $\mathrm{DB}_{\text {Frechet }} \sim 0.44\left(\mathrm{DB}_{\text {Frey }} \sim 0.38\right)$ are found, quite consistently with the results obtained by Žagar et al. on similar samples $\left(\mathrm{DB}_{\text {Frey }}=0.367^{[26]}\right)$. A value of $\mathrm{DB}=0.50$ would have been expected if all $\mathrm{OH}$ groups were equireactive in the bis(MPA) $\left(\mathrm{AB}_{2}\right)$ polyesterification reaction. A lower DB suggests that the terminal hydroxyls might have a higher reactivity in the original polyesterification. Finally, the average number of $\mathrm{OH}$ groups per constitutional repeating units, $\mathrm{n}_{\mathrm{CRU}}$, can be estimated from the ratio $\frac{2 \mathrm{~T}+\mathrm{L}}{\mathrm{D}+\mathrm{T}+\mathrm{L}}=2 \mathrm{~T}+\mathrm{L}($ since $\mathrm{D}+\mathrm{T}+\mathrm{L}=1)$. The average value lies around $1.08 \pm 0.04$. Theoretically, for a $4^{\text {th }}$ generation dendritic polymer based on a tetrafunctional core this value should be written as a function of the number average functionality, $f_{n}$, and degree of polymerization, $D P_{n}$ :

$$
\mathrm{n}_{\mathrm{CRU}}=\mathrm{z} / \mathrm{N}_{\mathrm{CRU}}=f_{n} / D P_{n}
$$


where $\mathrm{z}$ stands for the number of reactive groups per molecule and $\mathrm{N}_{\mathrm{CRU}}$ for the total number of CRU per molecule. More precisely in this case (dendrimer based on $\mathrm{AB}_{f B}$ monomer, core with functionality $f_{c}$ and generation $\left.\mathrm{G}\right)$ :

$$
\mathrm{z}=f_{c} f_{B}{ }^{\mathrm{G}} \text { and } \mathrm{N}_{\mathrm{CRU}}=f_{c}\left(\frac{f_{B}{ }^{G}-1}{f_{B}-1}\right) \text { or } \mathrm{n}_{\mathrm{CRU}}=\frac{f_{B}{ }^{G}\left(f_{B}-1\right)}{f_{B}{ }^{G}-1}=1.067 \quad\left(\mathrm{G}=4, f_{B}=2\right)
$$

The value found experimentally, although not so different, is thus slightly higher. NMR can also give some information on $D P_{n}$. According to Burgath et al. ${ }^{[35]}$, for a polycondensation involving an $\mathrm{AB}_{\mathrm{m}}$-type monomer and a core with $\mathrm{B}$ functionalities, $\mathrm{DP}_{\mathrm{n}}$ can be calculated by:

$$
D P_{n}=\frac{N(B)+N(A B)-\left(f_{c}-2\right) N_{c}}{N(B)-N(A B)-\left(f_{c}-2\right) N_{c}}
$$

where $N(B)=$ number of $\mathrm{B}$ functions, $N(A B)=$ number of $\mathrm{A}-\mathrm{B}$ bonds, $N_{c}=$ number of core molecules with a functionality $f_{c}$. In this work these parameters can be related to the ${ }^{1} \mathrm{H}$ NMR integrations, $\mathrm{I}$, of the various $\mathrm{CH}_{3}$ peaks (for methyl groups born by $\mathrm{D}, \mathrm{L}$ or $\mathrm{T}$ units, and therefore linked either to a $\mathrm{CH}_{2} \mathrm{OR}$ or $\mathrm{CH}_{2} \mathrm{OH}$ group). The integrations can be written as:

$$
\begin{aligned}
& I\left(\mathrm{CH}_{2} \mathrm{OH}\right)=\frac{4}{3} \mathrm{I}\left(\mathrm{CH}_{3}\right)_{T}+\frac{2}{3} I\left(\mathrm{CH}_{3}\right)_{L} \\
& I\left(\mathrm{CH}_{2} \mathrm{OR}\right)=\frac{4}{3} I\left(\mathrm{CH}_{3}\right)_{D}+\frac{2}{3} I\left(\mathrm{CH}_{3}\right)_{L}
\end{aligned}
$$

$\mathrm{I}\left(\mathrm{CH}_{2} \mathrm{OH}\right)$ is directly proportional to $\mathrm{N}(\mathrm{B})-\left(\mathrm{f}_{\mathrm{c}}-2\right) \mathrm{N}_{\mathrm{c}}$, and $\mathrm{I}\left(\mathrm{CH}_{2} \mathrm{OR}\right)$ to $\mathrm{N}(\mathrm{AB})$ with the same proportionality factor. Therefore $D P_{n}$ can be written as:

$$
D P_{n}=\frac{I\left(\mathrm{CH}_{3}\right)_{D}+I\left(\mathrm{CH}_{3}\right)_{L}+I\left(\mathrm{CH}_{3}\right)_{T}}{I\left(\mathrm{CH}_{3}\right)_{T}-\mathrm{I}\left(\mathrm{CH}_{3}\right)_{D}}=\frac{I\left(\mathrm{CH}_{3}\right)_{t o t}}{I\left(\mathrm{CH}_{3}\right)_{T}-I\left(\mathrm{CH}_{3}\right)_{D}}
$$

It is clear that a small variation in these integrations could induce a large error for $D P_{n}$ values. Taking into account the most accurate measurements (i.e. those obtained in the presence of TFA), the value obtained for $\mathrm{DP}_{\mathrm{n}}$ is 22.7 , thus (as expected) much less than the theoretical value of 60 for a perfect $4^{\text {th }}$ generation dendrimer. On another lot of HB40, Žagar et al. ${ }^{[26]}$ obtained values in the same range, $D P_{n}=22.4-23.8$, using $\mathrm{CH}_{2} \mathrm{OR}$ and $\mathrm{OH}$ signals 
and taking into account the presence of some labile protons. In contrast the very low value given by Burgath ${ }^{[35]}, D P_{n}=9.2$, can most probably be attributed to the fact that these labile protons were not considered when calculating the various peak integrations.

An estimation of the number average molar mass can finally be deduced from the value of $D P_{n}$ using $\mathrm{M}_{\mathrm{n}}=D P_{n} \mathrm{M}_{\mathrm{CRU}}+\mathrm{M}_{\mathrm{c}}+f_{n} \quad\left(\mathrm{M}_{\mathrm{CRU}}=115 \mathrm{~g} / \mathrm{mol}, \mathrm{M}_{\mathrm{c}}\right.$ [molar mass of the core moiety, pentaethoxylated pentaerythritol] $\sim 352 \mathrm{~g} / \mathrm{mol}$ and according to eq. $3 f_{n}=\mathrm{n}_{\mathrm{CRU}} \mathrm{DP}_{\mathrm{n}} \sim 24.5$ $\mathrm{OH} / \mathrm{molecule}$ ). This would lead to $\mathrm{M}_{\mathrm{n}} \sim 2990 \mathrm{~g} / \mathrm{mol}$. In another laboratory, the molar mass of the same HB40 sample was measured by SEC-MALLS at $\mathrm{M}_{\mathrm{n}}=2930 \mathrm{~g} / \mathrm{mol}^{[36]}$. Knowing the initial $\mathrm{OH}$ equivalent weight $\left(\mathrm{Eq}_{\mathrm{OH}}=8.4 \mathrm{~mol} / \mathrm{kg}\right)$ this would correspond to a value of $f_{n} \sim$ 24.6 OH/molecule. Both analyses, NMR and SEC-MALLS, are thus in very good agreement.

\section{Estimation of the modification degree, $t_{m}(\mathrm{OH}$ conversion)}

After completion of the modification reaction and drying steps, thermogravimetric analysis (TGA) was performed at first on the modified samples in order to check the absence of any residual isocyanate $\left(\mathrm{T}_{\mathrm{eb}}(\mathrm{pTI})=70-72^{\circ} \mathrm{C} / 10\right.$ torr or $\sim 195^{\circ} \mathrm{C} / 760$ torr $)$ or solvent. The results obtained for various modification degrees are shown in Figure 5. By checking with a coupled FTIR spectrometer, a slight loss of volatile compounds (mainly water and THF, but in any case lower than $0.5 \mathrm{wt} \%$ ) was indeed observed up to $170^{\circ} \mathrm{C}$; after that, the well-known thermal reversibility of the urethane bonds ${ }^{[37-38]}$ starts to interfere, with some pTI being evolved:

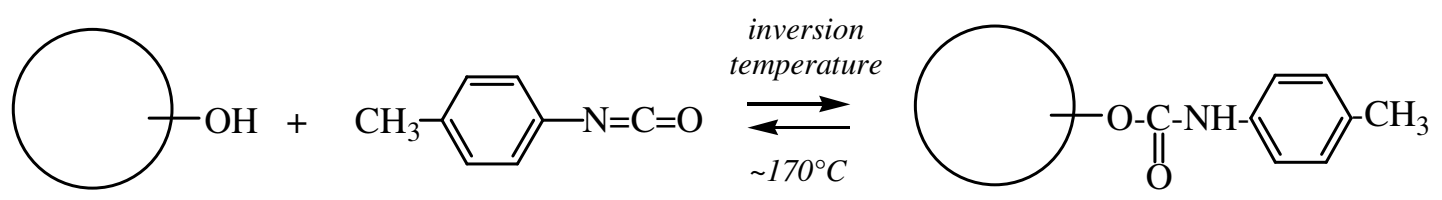

\section{Scheme 1}

Traces of p-toluidine could also be identified in this temperature range. It is clear from Figure 5 that the weight loss observed between 180 and $270^{\circ} \mathrm{C}$ is directly proportional to the 
amount of pTI used for the chemical modification. Since no residual isocyanate bond was detectable by FTIR in the initial material, pTI can only be produced through the thermal decomposition of urethane bonds. Above $275^{\circ} \mathrm{C}$, the products detected correspond mainly to the degradation of the HB polyester architecture itself. Moreover the various phenomena are always observed at the same temperatures, whatever the initial modification degree.

This modification degree, $\mathrm{t}_{\mathrm{m}}$, reflects the proportion of $\mathrm{OH}$ groups initially present in the HB molecules that have been converted to urethane groups by reaction with pTI. $t_{m}$ can thus be expressed as a function of the initial and final number average functionalities, $f_{n}$ :

$$
\mathrm{t}_{\mathrm{m}}=\frac{\mathrm{f}_{\mathrm{n}}(\mathrm{HB})-\mathrm{f}_{\mathrm{n}}\left(\mathrm{HB}_{\text {mod }}\right)}{\mathrm{f}_{\mathrm{n}}(\mathrm{HB})}
$$

Two different techniques, chemical titration and ${ }^{1} \mathrm{H}$ and ${ }^{13} \mathrm{C}$ NMR, were used and compared for the determination of $\mathrm{t}_{\mathrm{m}}$. The amount of modified $\mathrm{OH}$ groups was at first estimated by chemical titration. In this case the measurement directly leads to an $\mathrm{OH}$ equivalent weight, or number of $\mathrm{OH}$ groups per $\mathrm{kg}$ of the sample, $\mathrm{Eq}_{\mathrm{oH}}$. Consequently, the increment in molar mass induced by the presence of new p-tolyl urethane end groups must be taken into account in order to calculate $\mathrm{t}_{\mathrm{m}}$, which is given by the following equation:

$$
\mathrm{t}_{\mathrm{m}}=\frac{\mathrm{Eq}_{\mathrm{OH}}(\mathrm{HB})-\mathrm{Eq}_{\mathrm{OH}}\left(\mathrm{HB}_{\mathrm{mod}}\right)}{\mathrm{Eq}_{\mathrm{OH}}(\mathrm{HB})\left(1+\mathrm{Eq}_{\mathrm{OH}}\left(\mathrm{HB}_{\mathrm{mod}}\right) \cdot 10^{-3} \cdot \mathrm{M}_{\mathrm{pTI}}\right)}
$$

where $\mathrm{Eq}_{\mathrm{OH}}$ are the measured numbers of moles of $\mathrm{OH}$ groups $/ \mathrm{kg}$ for the various samples and $\mathrm{M}_{\mathrm{pTI}}$ stands for the molar mass of pTI in grams (133.15 $\left.\mathrm{g} / \mathrm{mol}\right)$.

These measurements were carried out on numerous samples prepared at various times during this study. All the values obtained for $t_{m}$ are reported as a function of the initially expected modification degree (i.e. the $\mathrm{NCO} / \mathrm{OH}$ ratio used for the modification reaction) in Figure 6 . The results are quite reproducible, but it is also clear that the value obtained for $t_{\mathrm{m}}$ is 
systematically lower than expected, and that the discrepancy is all the more pronounced as higher amounts of isocyanate were used. Part of this reagent $(15-20 \%)$ thus seems to have been lost in some side reaction. Although the reactions had been carried out using as dry as possible conditions, HB polyesters have been shown to be easily hydrated, especially on carbonyl sites, and the complete removal of water is difficult ${ }^{[27]}$. The most probable reaction would thus be the reaction of pTI with moisture, leading first to p-toluidine (I) and finally to a substituted urea (II):

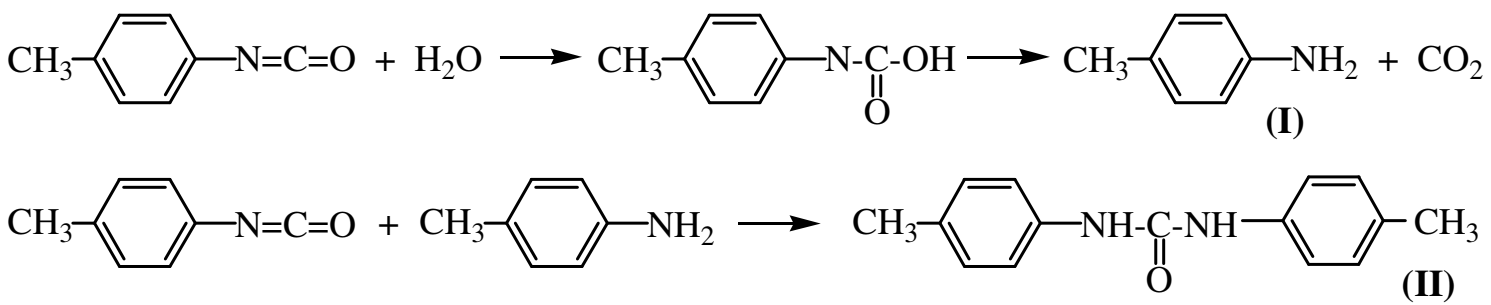

\section{Scheme 2}

Such species should not interfere with the chemical titration. Therefore the number of $\mathrm{OH}$ groups detected should be the actual one, provided that every hydroxyl function (whatever its position in the HB molecule, terminal or linear) is able to react with the titrating agent, tosylisocyanate. In the case of the non-modified $\mathrm{HB} 40$, a value of $\mathrm{Eq}_{\mathrm{OH}}$ equal to the theoretical value associated with the ideal dendrimeric structure, i.e. $8.4 \mathrm{~mol}_{\mathrm{OH}} / \mathrm{kg}$, was indeed found.

Of course, more information could be extracted from NMR data, and the above hypotheses could be confirmed. After modification of part of the $\mathrm{OH}$ groups by pTI, new pseudo-dendritic and pseudo-linear units are generated, and ${ }^{13} \mathrm{C}$ NMR can be as useful in detecting these units as in the case of the starting HB polyester ${ }^{[21]}$. All the units that can be found in a partially pTI-modified HB molecule are depicted in Figure $7 . \mathrm{D}_{\mathrm{i}}, \mathrm{L}_{\mathrm{i}}$ and $\mathrm{T}_{\mathrm{i}}$ are the initial dendritic, linear and terminal units, respectively; whereas $\mathrm{L}_{\mathrm{u}}$ is a new linear unit created by the reaction of a $T_{i}$ unit with one pTI; and $D_{1 u}$ and $D_{2 u}$ arise from the reaction of one pTI with $\mathrm{L}_{\mathrm{i}}$, or of two pTI with $\mathrm{T}_{\mathrm{i}}$ (i.e. 1 pTI with $\mathrm{L}_{\mathrm{u}}$ ), respectively. Using $N M R \mathrm{~L}_{\mathrm{i}}$ and $\mathrm{L}_{\mathrm{u}}$, or $\mathrm{D}_{\mathrm{i}}$, 
$D_{1 u}$ and $D_{2 u}$ cannot be entirely separated, but it is still possible to evaluate the global amounts of $\mathrm{D}, \mathrm{T}$ and $\mathrm{L}$ units.

In Figure 8 is presented the variation in the ${ }^{1} \mathrm{H}$ NMR spectra of the HB sample modified with 50\%pTI. After this modification, new peaks can be detected around $2.2 \mathrm{ppm}\left(\mathrm{CH}_{3}\right.$ bound to the aromatic ring) and between 7.0 and $7.3 \mathrm{ppm}$ (aromatic protons), but from these spectra it is not possible to tell whether pTI has indeed reacted with HB40 or not.

The ${ }^{13} \mathrm{C}$ spectrum of the same sample is shown in Figure 9. The various corresponding integrations are displayed in Table 2. The modified HB displays new $\mathrm{C}=\mathrm{O}$ peaks between 152.7 and $153.4 \mathrm{ppm}$, that can be attributed to urethane or urea groups. Aromatic carbons appear between 118.5 and 137.3 ppm, whereas the methyl group originating from pTI can be found at $20.2 \mathrm{ppm}$. A quantitative analysis of this last resonance allows to calculate the total amount of pTI-derived units with respect to $\mathrm{HB}$ (represented by the $\mathrm{CH}_{3}$ of the $\mathrm{D}, \mathrm{T}$ and $\mathrm{L}$ units), and thus to indirectly verify the amount of pTI that was initially added to HB40 (since the product was recovered by evaporation, see below). But it is also possible to go more into details: 3 types of carbonyl groups are indeed detectable, as well as several signals in the aromatic region that can be attributed to 2 different types of aromatic rings. After synthesizing the symmetrical urea (II) derived from pTI, it was possible to confirm that this compound was indeed present in the pTI-modified HB samples and could account for these multiple peaks.

As stated before, the chemical modification of $\mathrm{HB}$ also induces a change in the peaks associated with quaternary carbons, $\mathrm{Cq}$, carbonyls, $\mathrm{C}=\mathrm{O}$, and methyl groups of the $\mathrm{HB}$ constitutional repeating units (CRU). This evolution is particularly visible in the $\mathrm{Cq}$ area of HB40, HBpTI19 and HBpTI40 depicted in Figure 10. With increasing modification, a decrease in the intensity of T signals, as well as the appearance of new peaks in the $\mathrm{L}$ and $\mathrm{D}$ areas, are clearly visible. By comparing the global relative integrations of the 3 areas, i.e.:

$$
\mathrm{T}=\mathrm{T}_{\mathrm{i}}
$$




$$
\begin{array}{ll}
\mathrm{L}=\mathrm{L}_{\mathrm{i}}+\mathrm{L}_{\mathrm{u}} & (\text { with } \mathrm{D}+\mathrm{L}+\mathrm{T}=1) \\
\mathrm{D}=\mathrm{D}_{\mathrm{i}}+\mathrm{D}_{1 \mathrm{u}}+\mathrm{D}_{2 \mathrm{u}} &
\end{array}
$$

it is possible to estimate the relative number of $\mathrm{OH}$ groups per CRU, equal to $\mathrm{L}+2 \mathrm{~T}$. The proportion of converted $\mathrm{OH}$ groups, $\mathrm{t}_{\mathrm{m}}$, is thus given by:

$$
\mathrm{t}_{\mathrm{m}}=1-\frac{(\mathrm{L}+2 \mathrm{~T})_{\mathrm{HB} \text { mod }}}{(\mathrm{L}+2 \mathrm{~T})_{\mathrm{HB} 40}}
$$

Another possible way to estimate $t_{m}$ is to use the urethane carbonyl area since the peaks associated with $\mathrm{C}=\mathrm{O}$ (urethane) and $\mathrm{C}=\mathrm{O}$ (urea) are well separated, provided that a quantitative comparison of their integrations is possible. This was obtained by using an inversegate sequence with suppression of the NOE, and a delay of $10.72 \mathrm{~s}$ between 2 impulsions (pulse angle: $70^{\circ}$ ). Under such conditions $t_{m}$, which can also be considered as the urethane yield (proportion of initial $\mathrm{OH}$ groups that were used to produce urethanes), can be directly evaluated as:

$$
\mathrm{t}_{\mathrm{m}}=\frac{(\mathrm{C}=\mathrm{O})_{\text {urethane }}}{(\mathrm{L}+2 \mathrm{~T})_{\mathrm{HB} 40}}
$$

Finally, as the creation of 1 urea molecule (II) requires 2 pTI, the relative amount of isocyanate consumed by water, or urea yield, is equal to:

$$
\text { urea } \%=\frac{2(\mathrm{C}=\mathrm{O})_{\text {urea }}}{(\mathrm{L}+2 \mathrm{~T})_{\mathrm{HB} 40}}
$$

Whereas the total amount of pTI initially added to the HB polyester $\left(\mathrm{pTI} / \mathrm{OH}_{0}\right)$ can be verified from the integration of the aromatic methyl groups:

$$
\frac{[\mathrm{pTI}]_{0}}{[\mathrm{OH}]_{0}}=\frac{\left(\mathrm{CH}_{3}\right)_{\text {phenyl }}}{(\mathrm{L}+2 \mathrm{~T})_{\mathrm{HB} 40}}
$$

As shown in Table 2, this last value is obviously very close to the initially expected modification degrees $(12.5,25$ or $50 \%)$, but also to the sum $\left(t_{m}+\right.$ urea $\left.\%\right)$, which proves that all pTI molecules were consumed either in the modification of a hydroxyl end group or in the 
creation of a urea molecule (II). Moreover, both methods for the determination of $t_{m}$ (equations 14 and 15) lead to very similar results, which confirms the hypotheses made about $L_{u}, D_{1 u}$ and $D_{2 u}$ and validates the previous various estimations. But most important is the fact that the values of $t_{m}$ found by ${ }^{13} \mathrm{C}$ NMR are also consistent with the results obtained by chemical titration. This result allows to use titration, an easy and immediate technique, rather than the more complicated and rather time-consuming NMR as a systematic method to determine the modification degrees, $\mathrm{t}_{\mathrm{m}}$.

\section{Relative reactivities of "linear" and "terminal" hydroxyls}

Moreover, additional information can still be obtained from the NMR measurements, concerning the relative reactivities of the different types of $\mathrm{OH}$ groups (terminal, $\mathrm{T}$, or linear, $\mathrm{L})$. If the reaction between $\mathrm{NCO}$ and $\mathrm{OH}$ groups occurred statistically, $\mathrm{t}_{\mathrm{m}}$ would be equal to the probability of finding 1 reacted $\mathrm{OH}$ group, whereas $\left(1-\mathrm{t}_{\mathrm{m}}\right)$ would be the probability of finding 1 non-reacted $\mathrm{OH}$. Therefore during the chemical modification with a final conversion equal to $\mathrm{t}_{\mathrm{m}}$, an initial $\mathrm{T}$ unit could lead either to a final $\mathrm{L}_{\mathrm{u}}$ unit with a probability $2 * \mathrm{~T}_{\mathrm{i}} * \mathrm{t}_{\mathrm{m}} *(1-$ $t_{m}$ ), or to a final $D_{2 u}$ unit with a probability $T_{i} * t_{m} * t_{m}$, whereas an initial L unit could lead to a final $\mathrm{D}_{1 \mathrm{u}}$ unit with a probability $\mathrm{L}_{\mathrm{i}}{ }^{*} \mathrm{t}_{\mathrm{m}}$. If all these $\mathrm{OH}$ functions were equireactive, the final relative amounts of the 3 types of units $D_{\text {stat }}, L_{\text {stat }}$ and $T_{\text {stat }}$ after chemical modification $\left(t_{m}\right)$ could thus be directly written as a function of $t_{\mathrm{m}}$ :

$$
\begin{aligned}
& \mathrm{D}_{\text {stat }}=\mathrm{D}_{\mathrm{i}}+\mathrm{t}_{\mathrm{m}} \mathrm{L}_{\mathrm{i}}+\mathrm{t}_{\mathrm{m}}{ }^{2} \mathrm{~T}_{\mathrm{i}} \\
& \mathrm{L}_{\text {stat }}=\mathrm{L}_{\mathrm{i}}+2 \mathrm{t}_{\mathrm{m}}\left(1-\mathrm{t}_{\mathrm{m}}\right) \mathrm{T}_{\mathrm{i}}-\mathrm{t}_{\mathrm{m}} \mathrm{L}_{\mathrm{i}} \\
& \mathrm{T}_{\text {stat }}=\mathrm{T}_{\mathrm{i}}-2 \mathrm{t}_{\mathrm{m}}\left(1-\mathrm{t}_{\mathrm{m}}\right) \mathrm{T}_{\mathrm{i}}-\mathrm{t}_{\mathrm{m}}{ }^{2} \mathrm{~T}_{\mathrm{i}}
\end{aligned}
$$

(with $\mathrm{D}_{\mathrm{i}}+\mathrm{L}_{\mathrm{i}}+\mathrm{T}_{\mathrm{i}}=\mathrm{D}_{\text {stat }}+\mathrm{L}_{\text {stat }}+\mathrm{T}_{\text {stat }}$, and $\mathrm{OH}_{\text {stat }}=\mathrm{L}_{\text {stat }}+2 \mathrm{~T}_{\text {stat }}=\mathrm{OH}_{\mathrm{i}}\left(1-\mathrm{t}_{\mathrm{m}}\right)=\left(\mathrm{L}_{\mathrm{i}}+2 \mathrm{~T}_{\mathrm{i}}\right)\left(1-\mathrm{t}_{\mathrm{m}}\right)$ )

In Figure 11, these statistical results were plotted together with the actual values of D, L and $\mathrm{T}$ found for crude HB40 and for 3 modified samples. It appears that for every modified HB polymer, the real values of $\mathrm{D}$ and $\mathrm{T}$ are smaller than what would be expected for 
equireactive $\mathrm{OH}$ groups, whereas higher amounts of $\mathrm{L}$ units are systematically obtained as compared to the statistical values. This result proves that $\mathrm{OH}$ groups are indeed not equireactive, and more precisely that T-type hydroxyls are more reactive towards pTI than Ltype hydroxyls. This is also consistent with the low degree of branching found for these hyperbranched polymers (see above), with again unexpectedly high amounts of linear units in their structure: whatever the reaction (esterification or addition of an isocyanate), the latter seem to display a lower reactivity, maybe because of a better accessibility for terminal OHs. This has been explained in the literature in terms of a screening effect that would be most important for inner linear hydroxyls ${ }^{[39]}$. Also the reactivity of $\mathrm{OH}$ groups can be more or less affected by their ability to create hydrogen bonds; terminal $\mathrm{OHs}$ are more likely to be involved in hydrogen bonds with other hydroxyls, or even to remain free, whereas linear OHs inside the HB molecules are most probably linked to neighboring carbonyl groups. It has indeed been shown that these latter units were mainly responsible for the creation of ordered domains ${ }^{[29]}$; this could also account for a lower chemical reactivity.

As a result, the initial proportion of linear and terminal OHs (respectively 52/48 for the non modified HB polymer) becomes more and more unbalanced as the modification degree increases: HBpTI19 has $30 \% \mathrm{OH}_{\mathrm{T}}$ for $70 \% \mathrm{OH}_{\mathrm{L}}$, and $\mathrm{HBpTI} 40$ only $12 \% \mathrm{OH}_{\mathrm{T}}$ for $88 \% \mathrm{OH}_{\mathrm{L}}$. Therefore more and more modified HB samples will probably become less and less reactive.

\section{Effect of chemical modification on thermal and rheological behavior}

The thermal behavior of crude and modified HB polyesters was studied by Differential Scanning Calorimetry, DSC. Figure 12 shows the first and second runs obtained for all the samples. In the first scan (up to $140^{\circ} \mathrm{C}$ ), a strong endothermic phenomenon is visible above the glass transition, around $70^{\circ} \mathrm{C}$ for $\mathrm{HB} 40$, as well as for the samples with the lowest modification degrees (HBpTI4 and HBpTI8). This endotherm is most probably associated

with hydrogen bonds involving $\mathrm{OH}$ groups ${ }^{[27,29]}$ that would induce a pseudo-crystallization 
phenomenon, and would thus logically tend to disappear for the most modified samples. The second runs were obtained immediately after fast cooling (rate $\sim 50^{\circ} \mathrm{C} / \mathrm{min}$ ); and show two different phenomena. The first one, once again above $\mathrm{Tg}$ and between 50 and $100^{\circ} \mathrm{C}$, is clearly visible for non- or little-modified samples and disappears for higher values of $\mathrm{t}_{\mathrm{m}}$. In contrast, a new endothermic peak appears around $200^{\circ} \mathrm{C}$ for strongly modified samples that could not be detected for the others. Consequently, it would be logical to attribute the first peak to the ordering/disordering of domains formed by hydrogen bonds between $\mathrm{OH}$ groups, whereas the second peak would be due to the "melting" of quasi-crystalline domains formed by ordered aromatic urethane groups, linked by strong hydrogen bonds in a similar way as the hard segments found in segmented polyurethanes ${ }^{[30]}$. This hypothesis was confirmed by a WAXS analysis of the same samples, as shown in Figure 13. The spectrum obtained for crude HB40 displays only a broad peak centered on $2 \theta \approx 17.5^{\circ}$; whereas strongly modified samples display new sharp peaks at $2 \theta=6.5^{\circ}, 20^{\circ}$ and $26.5^{\circ}$, corresponding to characteristic lengths, d, equal to $13.8,4.4$ and $3.4 \AA$, respectively. In this same figure was also represented the WAXS spectrum of the model diurethane obtained by reacting bis(methylol)propionic acid (the base monomer of our HB polyester) with pTI:<smiles>Cc1ccc(NC(=O)Cc2ccc(NC(=O)CC(C)(COC(=O)Nc3ccc(C)cc3)C(=O)O)cc2)cc1</smiles>

\section{Scheme 3}

This partially crystalline material displays the same diffraction peak at $d=13.8 \AA$. This peak can consequently be related to a partial crystallization of the 4-methyl phenyl urethane chain ends in the modified samples, provided that the modification degree is high enough to allow the presence of a sufficient amount of urethane groups. 
Moreover, the second DSC scans also allow the determination of the glass transition temperature of the pristine and modified HB polyesters. The values obtained for numerous samples are represented as a function of $\mathrm{t}_{\mathrm{m}}$ in Figure 14. It is clear from this curve, as well as from Figure 12 that Tg increases linearly with the modification degree. In the literature, other chemical modifications of HB chain ends have been performed and resulted in variable effects on the glass transition temperature of the modified materials, but showing generally that $\mathrm{Tg}$ of HB polymers is mostly affected by the polarity of terminal groups ${ }^{[21,40]}$. For example using increasing amounts of long aliphatic chains induced a regular decrease in $\mathrm{Tg}{ }^{[41]}$. In contrast, in this work the creation of new rigid units, replacing rather weak hydrogen bonds between $\mathrm{OH}$ end groups by stronger bonds between urethanes results in an overall lower mobility for the ends of the branches of the HB molecule and therefore in an increase in $\mathrm{Tg}$, just like it could be observed for a linear telechelic oligomer endcapped with a monoisocyanate ${ }^{[42]}$.

Rheological measurements were also performed on the pristine HB40 and on modified samples at $110^{\circ} \mathrm{C}$, i.e. above both their glass transition and the first phenomenon detected by DSC. Under these conditions all of them, even those with the highest modification degrees, display a newtonian behavior (Figure 15). This means that no entanglement exists between the different $\mathrm{HB}$ molecules in the liquid state, even after a partial modification of the chain ends by a short, rigid moiety. Moreover this result also suggests that the interactions between urethane groups mentioned just above, and responsible for the endotherm at $200^{\circ} \mathrm{C}$, would rather be intramolecular and not intermolecular, otherwise the newtonian character would be altered below this temperature. This could be due both to the linear character of a great part of the initial $\mathrm{OH}$ groups and to a tendancy of the chain ends to fold back inside the molecule. The values obtained for the complex viscosity, $\eta^{*}$, nevertheless increase with increasing $t_{m}$, presumably simply as a consequence of the non-negligible increase in molar mass. More precisely, using the average molar mass measured by SEC-MALLS at $M_{n}=2930 \mathrm{~g} / \mathrm{mol}$ and 
the corresponding number average functionality, $\mathrm{f}_{\mathrm{n}} \mathrm{OH} \sim 24.6 \mathrm{OH} / \mathrm{molecule}^{[36]}$, with $\mathrm{t}_{\mathrm{m}}=64 \%$ $\mathrm{M}_{\mathrm{n}}$ would increase up to about $5030 \mathrm{~g} / \mathrm{mol}$. Indeed, hyperbranched polymers usually display an increase in their zero-shear viscosity with increasing generation and molar mass ${ }^{[4]}$. Concerning Boltorn $^{\mathrm{TM}}$ hyperbranched polyesters, their hydrodynamic radius was shown to scale as $\mathrm{R}_{\mathrm{h}} \sim \mathrm{M}^{0.39}{ }^{[5]}$. Moreover in a work on the rheological behavior of dendritic polymers, Sendijarevic showed that for a series of dendrimers with the same architecture, for a given generation the nature of the chain ends also had a very important effect on the viscosity ${ }^{[4]}$.

Other measurements were also carried out using temperature $\left(20-150^{\circ} \mathrm{C}\right)$ and frequency $\left(1,10,100 \mathrm{rad}_{\mathrm{s}} \mathrm{s}^{-1}\right)$ sweeps. Only one $\alpha$ relaxation was detected in the G" and tan $\delta$ spectra, in agreement with the microcalorimetric studies. Another interesting feature is the rheological behavior of these samples at high temperature, as depicted in Figure 16. Three samples (pristine $\mathrm{HB} 40$, and samples with $\mathrm{t}_{\mathrm{m}}=19$ or $40 \%$ ) were characterized at three different frequencies $\left(\omega=1,10\right.$ and $\left.100 \mathrm{rad} . \mathrm{s}^{-1}\right)$. The overall behavior can be seen in Figure 16a. At low temperature, $\eta^{*}$ depends mainly on the pulsation as the samples are in the glassy state, whatever their modification degree. When increasing temperature, these three groups of curves progressively diverge as the samples find themselves above their $\mathrm{Tg}$; at such temperatures three new groups of curves are formed when the curves associated with a particular value of $\mathrm{t}_{\mathrm{m}}$ merge: above $\mathrm{Tg}$ and up to about $110^{\circ} \mathrm{C}, \eta^{*}$ depends only on $\mathrm{t}_{\mathrm{m}}$, whatever the frequency, consistently with their newtonian behavior already depicted in Figure 15. But at even higher temperature, a new phenomenon occurs that is more easily seen in Figure $16 \mathrm{~b}$. Whereas pristine HB40 keeps its newtonian behavior up to $160^{\circ} \mathrm{C}$ (blue curves), this character is lost for modified samples above $110-120^{\circ} \mathrm{C}$, with an increase in viscosity observed especially for lower frequencies. No special phenomenon was detected by TGA in this temperature range (see Figure 5); moreover, a new chemical titration of the hydroxyl functions was carried out on the samples after these rheological measurements and revealed 
that the $\mathrm{OH}$ equivalent weights were exactly the same as before the experiment (for example before the experiment $\mathrm{Eq}_{\mathrm{OH}}(\mathrm{HBpTI} 40)=3.52 \mathrm{~mol} / \mathrm{kg}$, after the experiment $\left.3.51 \mathrm{~mol} / \mathrm{kg}\right)$; therefore no side reaction inducing molecular coupling (such as etherification between two $\mathrm{OH}$ chain ends) must have occurred. In the same way, no difference could be observed in the size exclusion chromatograms of the samples before and after the measurement. Finally a DSC analysis of these samples was performed. After a first scan up to $150^{\circ} \mathrm{C}$ to eliminate all low-temperature phenomena, they were cooled back to room temperature $\left(-50^{\circ} \mathrm{C} / \mathrm{min}\right)$ and heated up again to $250^{\circ} \mathrm{C}$ at $10^{\circ} \mathrm{C} / \mathrm{min}$. Figure 17 displays the curves obtained for HBpTI40 before and after the rheological analysis. For the latter sample, $\mathrm{Tg}$ is slightly higher $\left(44^{\circ} \mathrm{C}\right.$ instead of $42^{\circ} \mathrm{C}$ ), but the endotherms are also detected at higher temperature. Therefore the loss of newtonian behavior might be due to a better ordering of the already existing tolyl urethane domains, together with the establishment of new intermolecular interactions between tolyl urethane (end)groups. They could be favored by the slow increase $\left(3^{\circ} \mathrm{C} / \mathrm{min}\right)$ in temperature as it approaches that of the "melting" of such ordered domains, observed above $150^{\circ} \mathrm{C}$ in the $\mathrm{DSC}$ traces recorded at $10^{\circ} \mathrm{C} / \mathrm{min}$. In a similar way, at high temperature segmented polyurethanes often display successive endotherms associated first with the micromixing of soft and hard domains, and slightly above with the melting of microcrystalline hard segments ${ }^{[43-46]}$. Annealing at increasing temperature (between 120 and $200^{\circ} \mathrm{C}$ ) has often been shown to induce a better ordering of the domains and thus to result in an increase in the intermediate endotherm temperature; the same kind of phenomenon could be observed in this work.

\section{Conclusions}

A commercial hyperbranched polyester with multiple hydroxyl functional groups, HB40, was partially endcapped using p-tolylisocyanate, pTI, in order to obtain potential crosslinkers 
that would be miscible with usual polyurethane precursors (macrodiol and diisocyanate). The final microstructure of the modified samples was then characterized with the help of ${ }^{1} \mathrm{H}$ and ${ }^{13} \mathrm{C}$ NMR and the results compared with those of a chemical titration. The latter proved to be sufficient for a first approximation of the $\mathrm{OH}$ conversion or modification degree, $\mathrm{t}_{\mathrm{m}}$. However NMR allows a more precise determination of $\mathrm{t}_{\mathrm{m}}$, and also the estimation of the amount of pTI lost in a side reaction with moisture leading to non-reactive urea molecules.

Moreover, the use of NMR proved that $\mathrm{OH}$ groups belonging to linear bis(MPA) units were less reactive than those born by terminal bis(MPA) units, thus inducing a progressive decrease in the reactivity of increasingly modified samples that obviously bear increasing proportions of linear units.

This chemical modification was also shown to induce an overall increase in the $\mathrm{Tg}$ of these hyperbranched oligomers, as well as the creation of partially ordered domains between urethane groups for the samples with the highest modification degrees. The modified samples seem to be stable up to quite a high temperature, however their newtonian behavior tends to be altered by long annealing above $110-120^{\circ} \mathrm{C}$, suggesting additional intermolecular associating phenomena. All these important parameters will have to be considered for the synthesis of the polyurethane networks, that will be described in a coming paper. 


\section{Acknowledgements}

This work was initially undertaken within the framework of a European Copernicus Program on "Environmentally friendly crosslinked polyurethane materials from precursors of compact architecture". Fruitful discussion with all the participants, and especially the help of Prof. M. Žigon and Dr E. Žagar for SEC-MALLS measurements, is gratefully acknowledged.

\section{References}

1. M. Johansson, E. Malmström, A. Hult, Trends Polym. Sci. 4 (1996) 398.

2. B. Voit, J. Polym. Sci., Part A: Polym. Chem. 38 (2000) 2505.

3. K. L. Wooley, J. M. Frechet, C. J. Hawker, Polymer 35 (1994) 4489.

4. I. Sendijarevic, A. J. McHugh, Macromolecules 33 (2000) 590.

5. C. M. Nunez, B. S. Chiou, A. L. Andrady, S. A. Khan, Macromolecules 33 (2000) 1720.

6. T. T. Hsieh, C. Tiu, G. P. Simon, Polymer 42 (2001) 1931.

7. Y. H. Kim, O. W. Webster, Macromolecules 25 (1992) 5561.

8. D. J. Massa, K. A. Shriner, S. R. Turner, B. I. Voit, Macromolecules 28 (1995) 3214.

9. D. Schmaljohann, P. Pötschke, R. Hässler, B.I. Voit, P.E. Froehling, B. Mostert, J.A. Loontjens, Macromolecules 32 (1999) 6333.

10. T. J. Mulkern, N. C. Beck Tan, Polymer 41 (2000) 3193.

11. H. Wu, J. Xu, Y. Liu, P. Heiden, J. Appl. Polym. Sci. 72 (1998) 151.

12. L. Boogh, B. Petterson, J. A. E. Månson, Polymer 40 (1999) 2249.

13. R. Mezzenga, C. J. G. Plummer, L. Boogh, J. A. E. Månsson, Polymer 42 (2001) 305.

14. B. I. Voit, S. R. Turner, Angew. Makromol. Chem. 223 (1994) 13.

15. B. I. Voit, Acta Polymerica 46 (1995) 87.

16. S. R. Turner, B. I. Voit, T. H. Mourey, Macromolecules 26 (1993) 4617.

17. S. R. Turner, F. Walter, B. I. Voit, T. H. Mourey, Macromolecules 27 (1994) 1611. 
18. R. Scherrenberg, B. Coussens, P. van Vliet, G. Edouard, J. Brackman, E. de Brabander, Macromolecules 31 (1998) 456.

19. K. L. Wooley, C. J. Hawker, R. Lee, J. M. J. Frechet, Polym. J. 26 (1994) 187.

20. A. R. Brenner, B. I. Voit, D. J. Massa, S. R. Turner, Macromol. Symp. 102 (1996) 47.

21. E. Malmström, M. Johansson, A. Hult, Macromolecules 28 (1995) 1698.

22. E. Malmström, A. Hult, Macromolecules 29 (1996) 1222.

23. H. Ihre, A. Hult, E. Söderlink, J. Am. Chem. Soc. 118 (1996) 6388.

24. H. Magnusson, E. Malmström, A. Hult, Macromolecules 33 (2000) 3099.

25. H. Komber, A. Ziemer, B. Voit, Macromolecules 35 (2002) 3514.

26. E. Zagar, M. Zigon, Macromolecules 2002, 35, 9913-9925.

27. E. Zagar, J. Grdadolnik, J. Mol. Struct. 2003, 658, 143-152.

28. E. Zagar, M. Zigon, J. Chromatography A 2004, 1034, 77-83.

29. E. Zagar, M. Husvik, J. Grdadolnik, M. Zigon, A. Zupancic-Valant, Macromolecules 2005, 38, 3933-3942.

30. L. Cuvé, J.P. Pascault, G. Boiteux, Polymer 33 (1992) 3957.

31. E. Cognet-Georjon, F. Méchin, J.P. Pascault, Macromol. Chem. Phys. 197 (1996), 3593.

32. B. Nabeth, I. Corniglion, J.P. Pascault, J. Polym. Sci., Part B: Polym. Phys. 34 (1996) 401.

33. P. Barbeau, J.F. Gérard, B. Magny, J.P. Pascault, J. Polym. Sci., Part B: Polym. Phys. 38 (2000) 2750 .

34. I. Henry, J.P. Pascault, M. Taha, G. Vigier, J.J. Flat, J. Appl. Polym. Sci. 83 (2002) 225.

35. A. Burgath, A. Sunder, H. Frey, Macromol. Chem. Phys. 201 (2000) 782.

36. E. Zagar, M. Zigon, private communication.

37. Y. Camberlin, J.P. Pascault, J.M. Letoffé, P. Claudy, J. Polym. Sci. Polym. Chem. Ed. 20 (1982) 383. 
38. W.P. Yang, C.W. Macosko, S.T. Wellinghoff, Polymer 27 (1986) 1235.

39. R. Pruthtikul, M. Coleman, P. Painter, N.B. Tan, Macromolecules 34 (2001) 4145.

40. K. L. Wooley, C. J. Hawker, J. M. Pochan, J. M. J. Fréchet, Macromolecules 26 (1993) 1514.

41. E. Malmström, M. Johansson, A. Hult, Macromol. Chem. Phys. 197 (1996) 3199.

42. Z.S. Chen, W.P. Yang, C.W. Macosko, Rubber Chem. Technol. 61 (1988) 86.

43. J.T. Koberstein, T.P. Russell, Macromolecules 19 (1986) 714.

44. J.T. Koberstein, A.F. Galambos, Macromolecules 25 (1992) 5618.

45. A. Saiani, W.A. Daunch, H. Verbeke, J.W. Leenslag, J.S. Higgins, Macromolecules 34 (2001) 9059 .

46. A. Saiani, C. Rochas, G. Eeckhaut, W.A. Daunch, J.W. Leenslag, J.S. Higgins, Macromolecules 37 (2004) 1411. 
Table $1:{ }^{1} \mathrm{H}$ (without or with trifluoroacetic acid, TFA) and ${ }^{13} \mathrm{C}$ NMR (ig: inversegate) analysis of pristine HB40

\begin{tabular}{|c|c|c|c|c|c|c|}
\hline & $\mathbf{D}$ & $\mathbf{L}$ & $\mathbf{T}$ & $\mathbf{D B}_{\text {Frechet }}$ & $\begin{array}{c}\text { Average number } \\
\text { of OH/unit } \\
(\mathbf{2 T}+\mathbf{L})\end{array}$ \\
\hline $\mathrm{CH}_{3}\left({ }^{1} \mathrm{H}, 1.0-1.4 \mathrm{ppm}\right)$ & 0.199 & 0.518 & 0.283 & 0.48 & 0.43 & 1.084 \\
$\mathrm{CH}_{3}\left({ }^{1} \mathrm{H}, 1.0-1.4 \mathrm{ppm}\right)$ with TFA & 0.198 & 0.560 & 0.242 & 0.44 & 0.41 & 1.044 \\
$\mathrm{C}=\mathrm{O}\left({ }^{13} \mathrm{C}, \mathrm{ig}, 171-175 \mathrm{ppm}\right)$ & 0.161 & 0.551 & 0.287 & 0.45 & 0.37 & 1.125 \\
$\mathrm{Cq}\left({ }^{13} \mathrm{C}, \mathrm{ig}, 45-51 \mathrm{ppm}\right)$ & 0.178 & 0.552 & 0.265 & 0.45 & 0.39 & 1.083 \\
\hline
\end{tabular}


Table 2: NMR analysis of HB40 and of 3 increasingly modified samples, and various values deduced from peak integrations

\begin{tabular}{|c|c|c|c|c|c|c|c|c|c|c|c|c|c|c|}
\hline Sample & $\begin{array}{c}\text { Expected } \\
\operatorname{tm}(\%)\end{array}$ & $\begin{array}{c}\text { D } \\
(\mathbf{C q})\end{array}$ & $\begin{array}{c}\mathbf{L} \\
(\mathbf{C q})\end{array}$ & $\begin{array}{c}\mathbf{T} \\
(\mathbf{C q})\end{array}$ & $\begin{array}{c}\text { average } \\
\text { number } \\
\text { of } \\
\text { OH/CRU } \\
(\mathrm{L}+2 \mathrm{~T}) \\
\end{array}$ & $\begin{array}{c}\mathrm{C}=\mathrm{O} \\
\text { urethane }\end{array}$ & $\begin{array}{l}\mathrm{C}=\mathbf{O} \\
\text { urea }\end{array}$ & $\begin{array}{c}\mathrm{CH}_{3} \\
\text { phenyl }\end{array}$ & $\begin{array}{c}\mathbf{t}_{\mathbf{m}} \\
\text { from } \\
\mathrm{D}, \mathrm{L}, \mathrm{T} \\
(\%)\end{array}$ & $\begin{array}{c}\mathbf{t}_{\mathbf{m}} \\
\text { from } \\
\mathrm{C}=\mathbf{O}\end{array}$ & $\begin{array}{c}\mathbf{t}_{\mathrm{m}} \text { from } \\
\text { titration }\end{array}$ & $\begin{array}{c}\text { urea } \\
\text { yield } \\
\%\end{array}$ & $\begin{array}{c}\begin{array}{c}\mathbf{t}_{\mathrm{m}} \\
(\mathrm{mean}\end{array} \\
\text { value) } \\
+\mathrm{u} \%\end{array}$ & $\begin{array}{c}\mathbf{p T I} \\
/ \\
\text { initial } \mathrm{OH} \\
\text { (from } \\
\mathrm{CH}_{3} \text { phenyl) }\end{array}$ \\
\hline HB40 & 0 & 0.178 & 0.552 & 0.265 & 1.083 & 0 & 0 & 0 & 0 & 0 & 0 & 0 & 0 & 0 \\
\hline НВрТІ9 & 12.5 & 0.209 & 0.597 & 0.194 & 0.985 & 0.109 & 0.017 & 0.154 & 9.6 & 10.0 & 8.7 & 3.1 & 12.9 & 14.2 \\
\hline HВрТI19 & 25 & 0.252 & 0.613 & 0.136 & 0.885 & 0.177 & 0.031 & 0.251 & 18.7 & 16.3 & 19.0 & 5.7 & 23.2 & 23.2 \\
\hline HBрTI40 & 50 & 0.351 & 0.604 & 0.045 & 0.694 & 0.414 & 0.051 & 0.536 & 36.3 & 38.0 & 40.5 & 9.4 & 46.6 & 49.5 \\
\hline
\end{tabular}




\section{Figure captions}

Figure 1: Ideal reaction scheme for the synthesis of well-defined polyurethane networks based on hyperbranched crosslinking agents

Figure 2: Typical structure of a third-generation hyperbranched polyester based on bis(MPA)

Figure 3: ${ }^{1} \mathrm{H}$ and ${ }^{13} \mathrm{C}$ NMR spectra of the fourth-generation hyperbranched polyester (HB40, Boltorn $\left.^{\mathrm{TM}} \mathrm{H} 40\right) ; \mathrm{s}=$ protonated residue of DMSO-d6

Figure 4: Determination of D, L and T units by NMR. a) ${ }^{1} \mathrm{H}, \mathrm{CH}_{3}$; b) ${ }^{13} \mathrm{C}, \mathrm{Cq}$; c) ${ }^{13} \mathrm{C}, \mathrm{C}=\mathrm{O}$

Figure 5: Thermogravimetric analysis of pristine HB40 (*) and of HB40 modified with various proportions of pTI; $\diamond: 8 \% ; \triangle: 19 \% ; \bigcirc: 40 \%$

Figure 6: Actual modification degree, $\mathrm{t}_{\mathrm{m}}$, obtained as a function of the expected value (initial $[\mathrm{NCO}] /[\mathrm{OH}]$ ratio)

Figure 7: Various D, L and T units in a partially pTI-modified HB polyester sample

Figure 8: ${ }^{1} \mathrm{H}$ NMR spectrum of HB40 modified with $50 \%$ pTI $\left(\mathrm{t}_{\mathrm{m}}=40 \%\right)$; s = protonated residue of DMSO-d6

Figure 9: ${ }^{13} \mathrm{C}$ NMR spectrum of HB40 modified with $50 \%$ pTI $\left(\mathrm{t}_{\mathrm{m}}=40 \%\right)$

Figure 10: $\mathrm{Cq}$ area in the ${ }^{13} \mathrm{C}$ NMR spectra of a) pristine HB40; b) HBpTI19; c) HBpTI40

Figure 11: Variation of the proportion of D, L and T units with tm; (..., open symbols): all OHs equireactive; (一, full symbols): experimental values

Figure 12: DSC curves for pristine and variously modified HB40 samples: * : pristine HB40; HBpTI4; $\diamond:$ HBpTI8; $\triangle$ : HBpTI19; $:$ HBpTI40; a) first scans; b) second scans after rapid cooling $\left(-50^{\circ} \mathrm{C} / \mathrm{min}\right)$.

Figure 13: WAXS analysis of pristine HB40 and of two pTI-modified samples; comparison with pTI-modified bis(MPA).

Figure 14: Glass transition temperature of the variously modified HB samples (from second DSC scans) as a function of their measured modification degree, $\mathrm{t}_{\mathrm{m}}$.

Figure 15: Complex viscosity of pristine $\mathrm{HB} 40$ and of 3 modified samples at $110^{\circ} \mathrm{C}$. 
Figure 16: Complex viscosity of pristine and modified HB40 during a temperature scan $\left(3^{\circ} \mathrm{C} / \mathrm{min}\right)$ from room temperature up to $150^{\circ} \mathrm{C} ; *$ : HB40; $\triangle$ : HBpTI19; $\bigcirc$ : HBpTI40; clear color: 1 rad.s ${ }^{-1}$; medium color: 10 rad.s ${ }^{-1}$; dark color: 100 rad.s ${ }^{-1}$.

Figure 17: DSC analysis (second scan, after a first scan from $-30^{\circ} \mathrm{C}$ to $150^{\circ} \mathrm{C}$ at $10^{\circ} \mathrm{C} / \mathrm{min}$ and fast cooling) of HBpTI40: ( $\square$ ) before rheological characterization; ( $\square$ ) after rheological characterization. 
Figure 1

$\mathrm{HO} \Omega \Omega \Omega \sim s$ oft segment $\Omega \Omega \Omega \sim \mathrm{OH}+(\mathrm{x}+1) \quad \mathrm{O}=\mathrm{C}=\mathrm{N}-\square-\mathrm{N}=\mathrm{C}=\mathrm{O}$

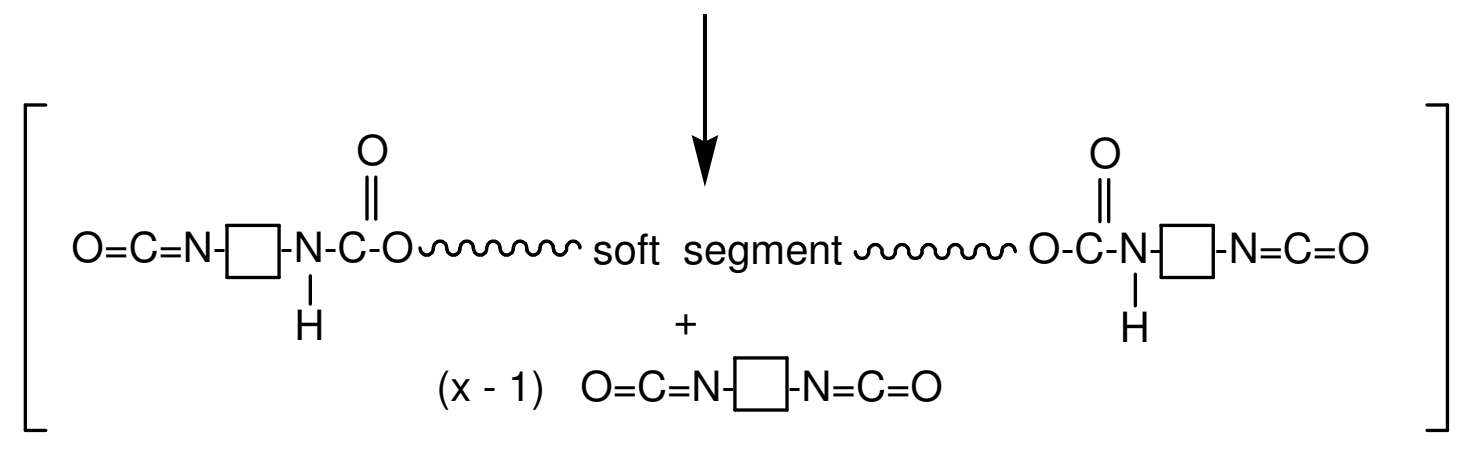

diisocyanate prepolymer

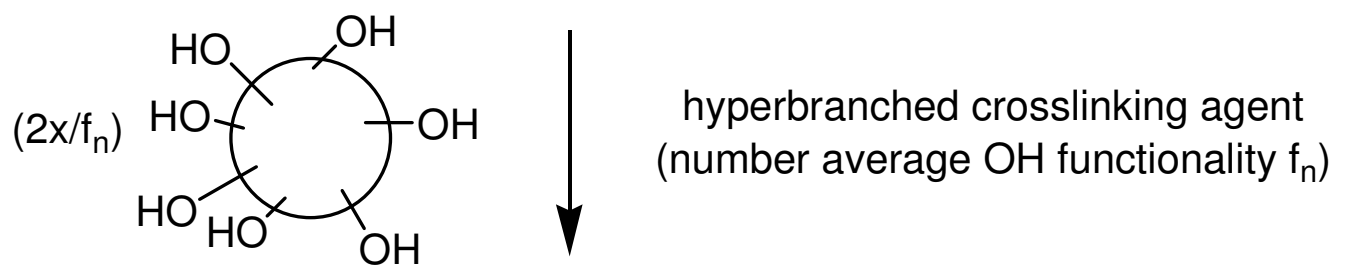

well-defined polyurethane network 
Figure 2

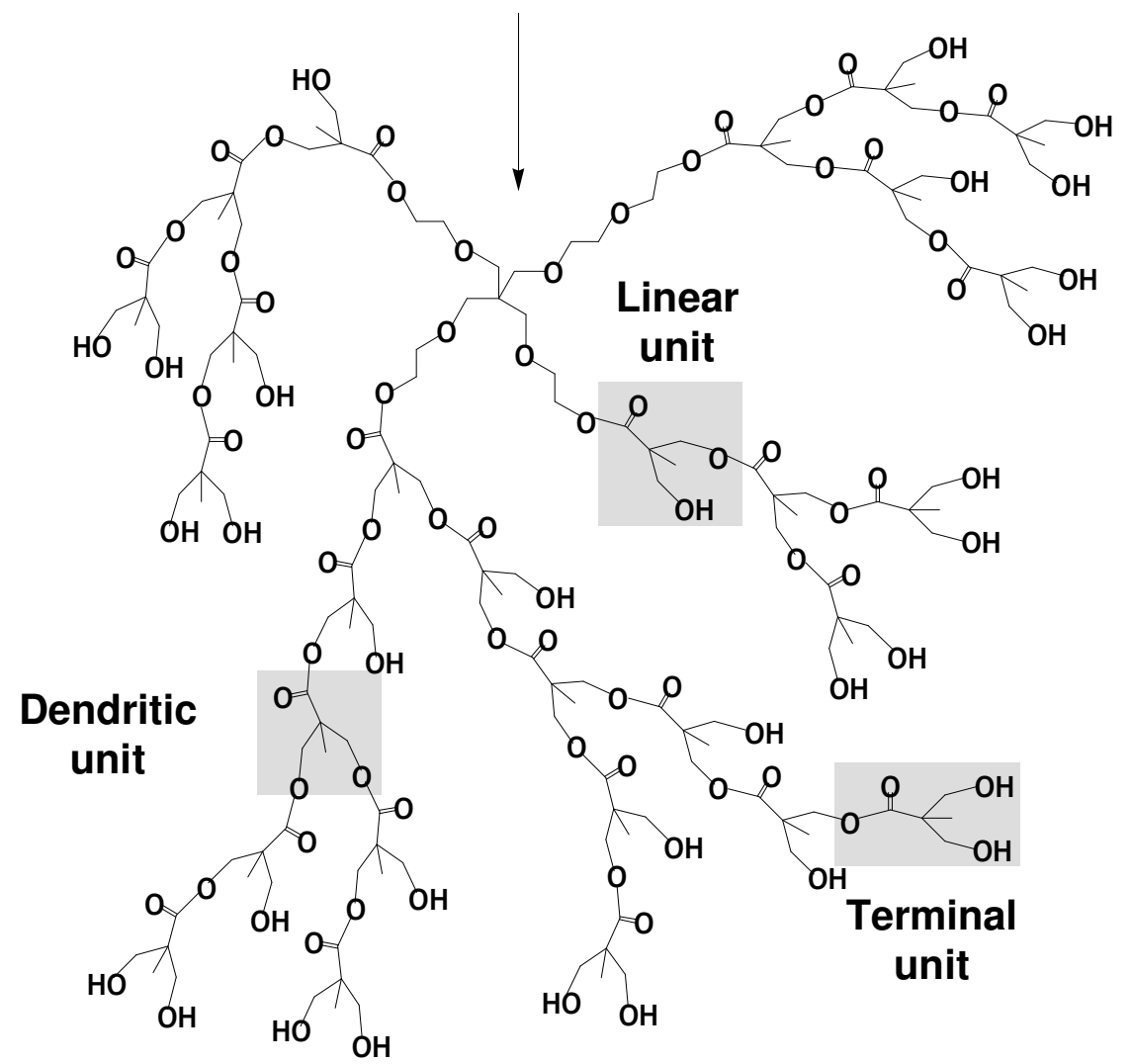


Figure 3

a)

* : labile H

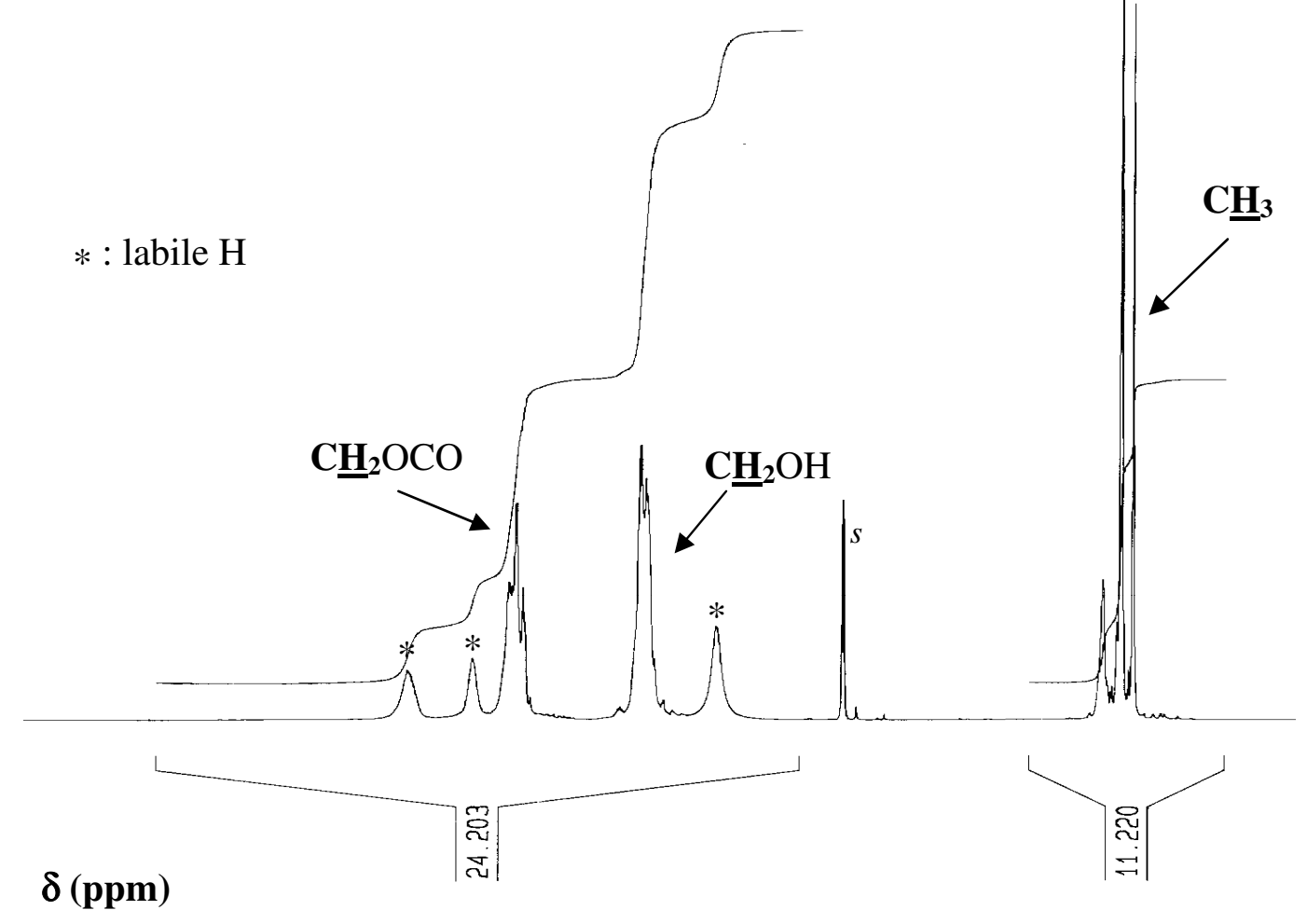

b)

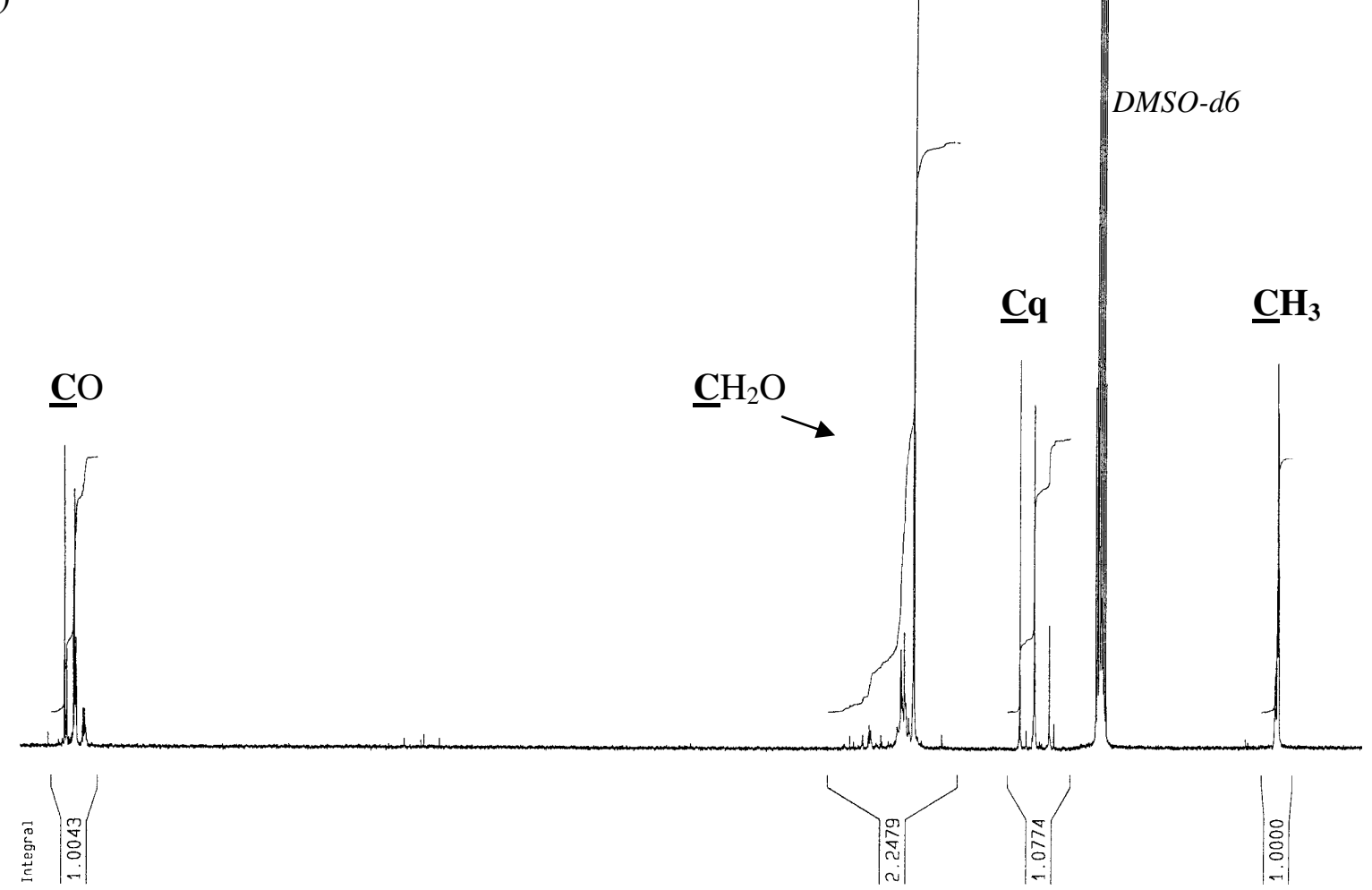


Figure 4

a)

L

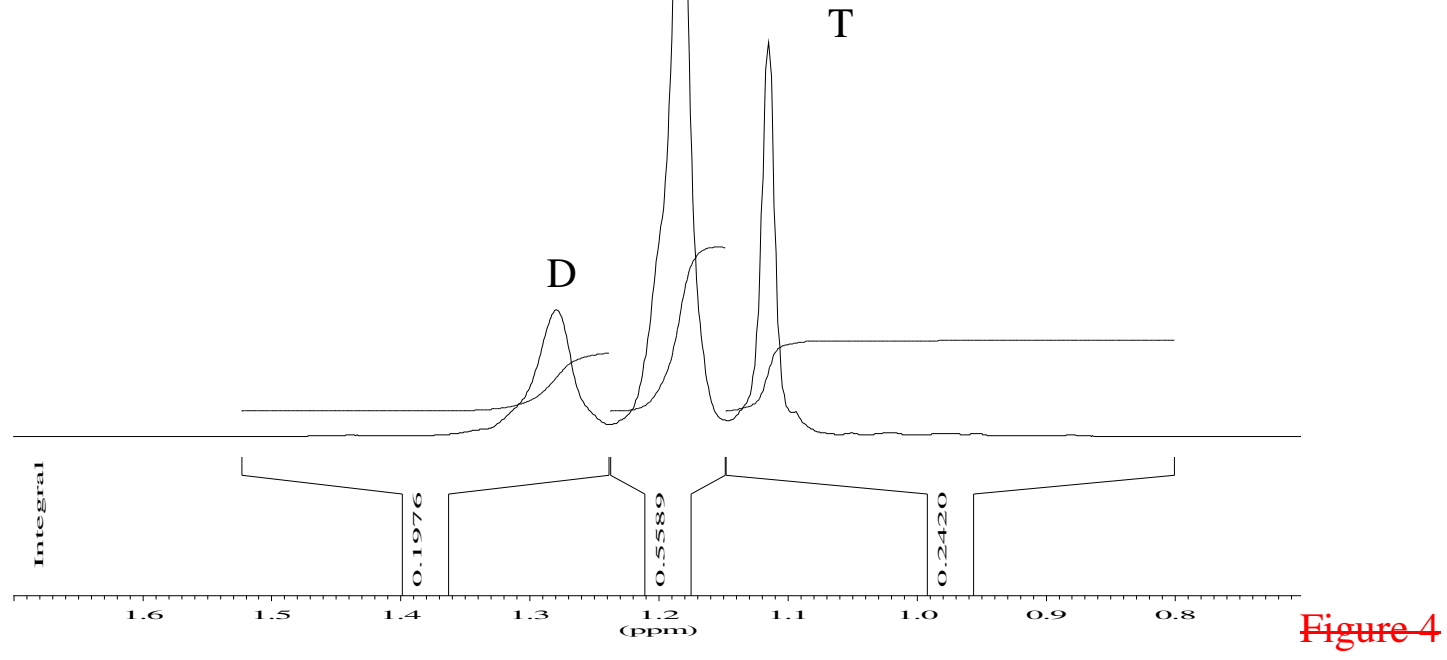

b)
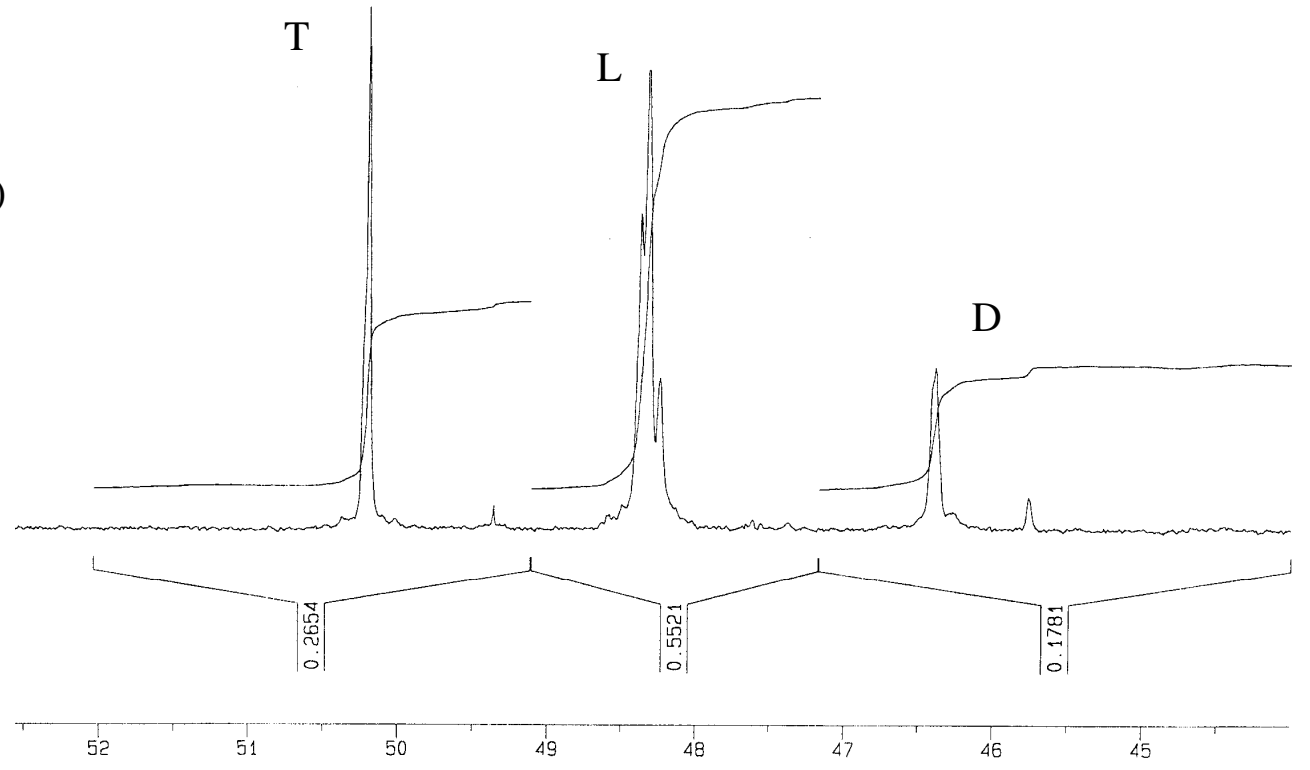

c)

L

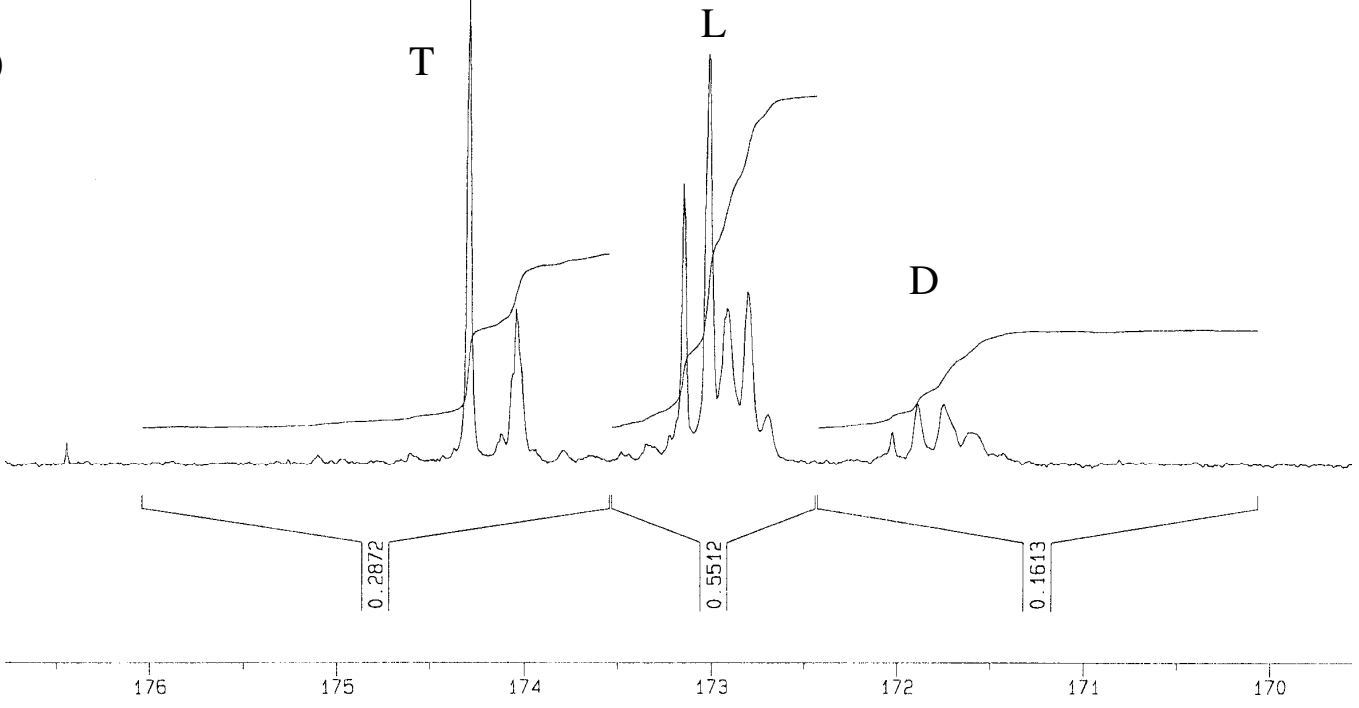


Figure 5

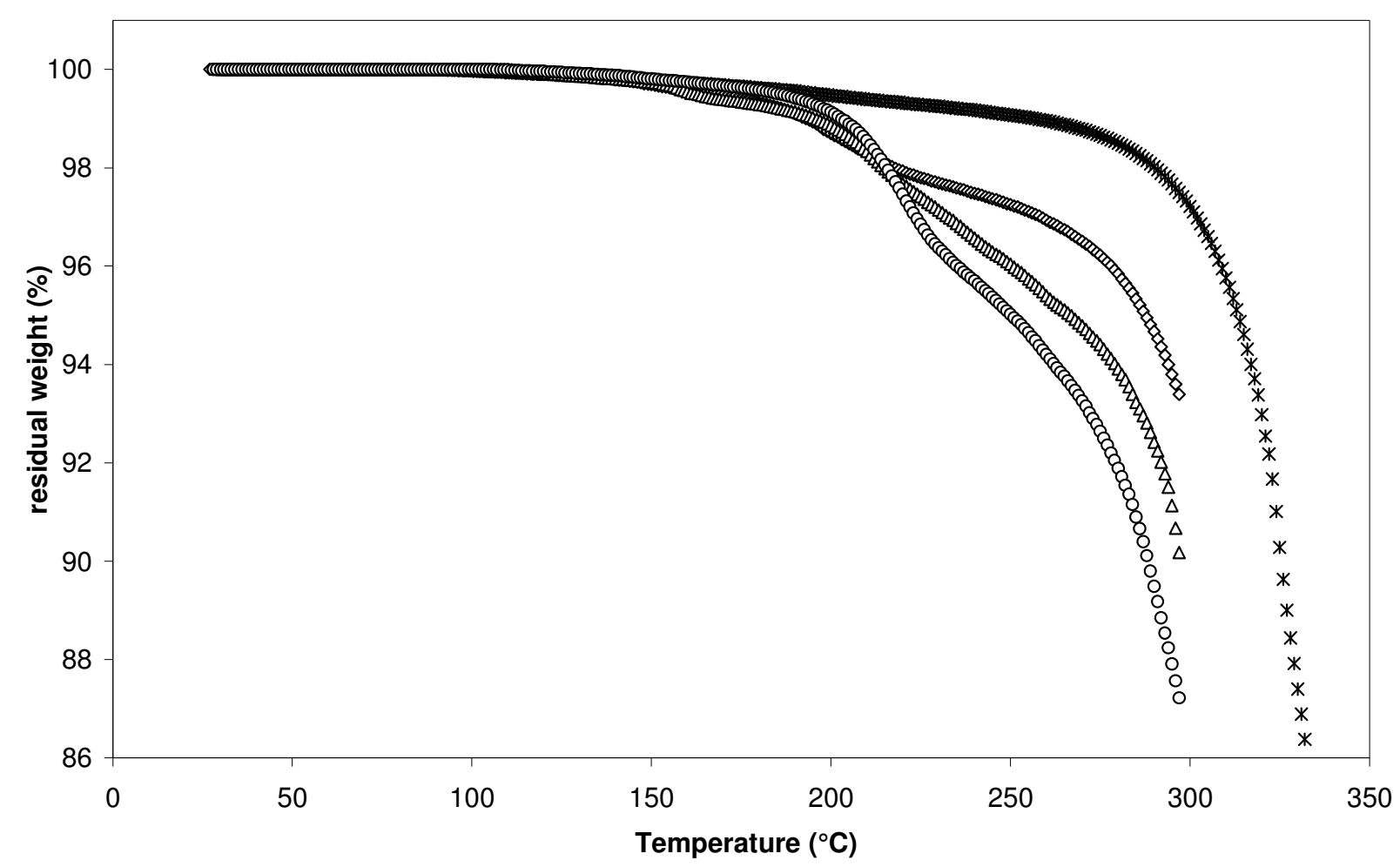


Figure 6

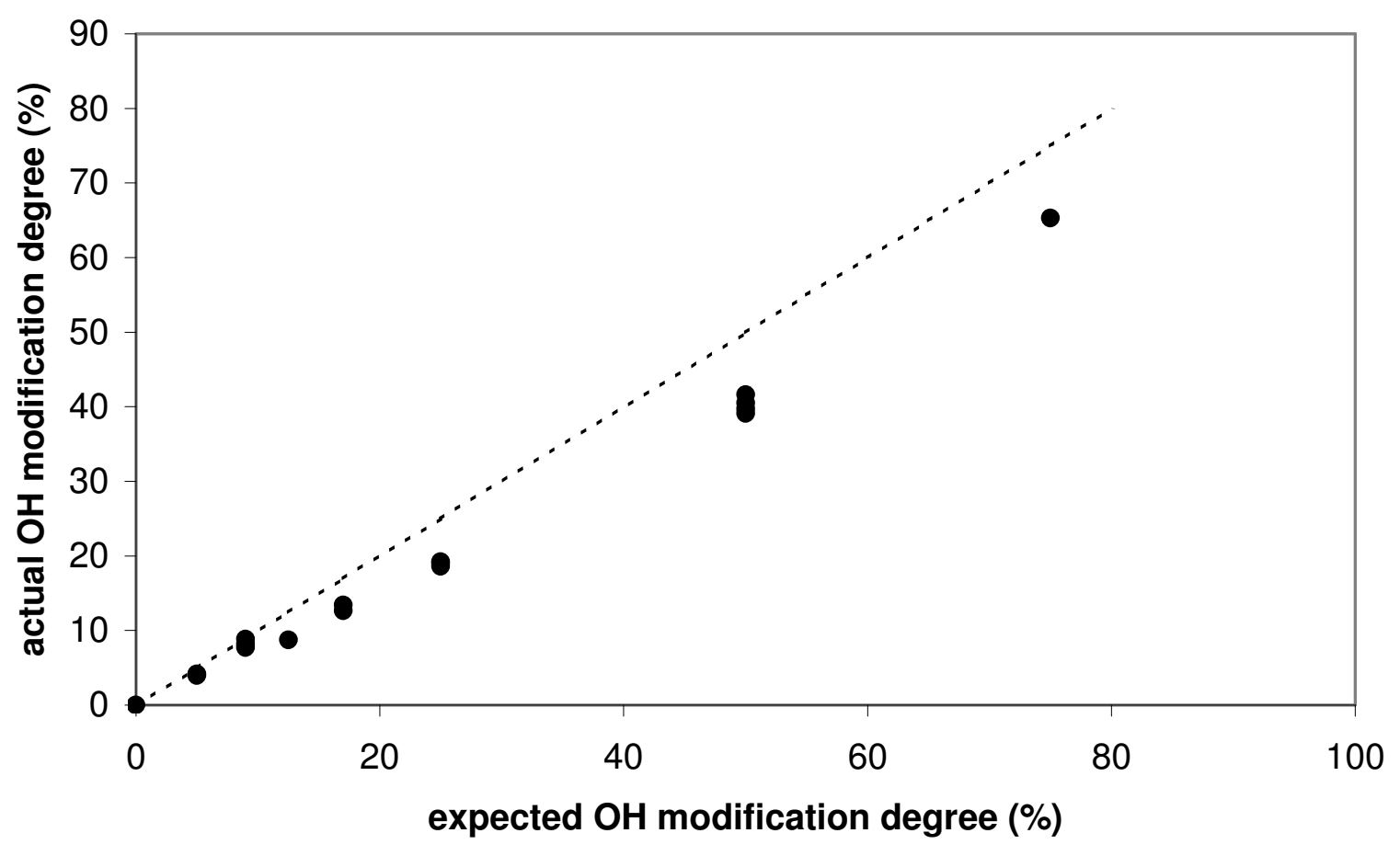


Figure 7

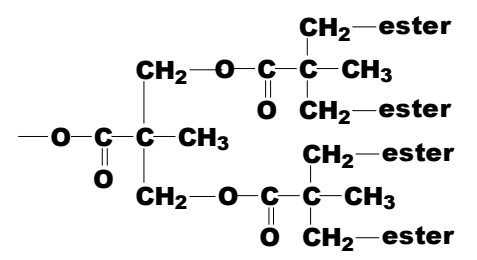

$$
\begin{aligned}
& \mathrm{D}_{\mathrm{i}}
\end{aligned}
$$

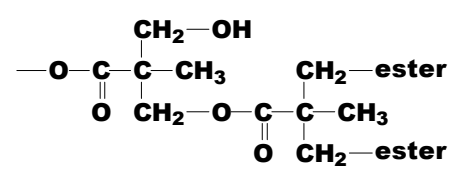

$$
\begin{aligned}
& \mathrm{L}_{\mathrm{i}} \\
& \underset{\mathrm{pTI}}{\longrightarrow}
\end{aligned}
$$

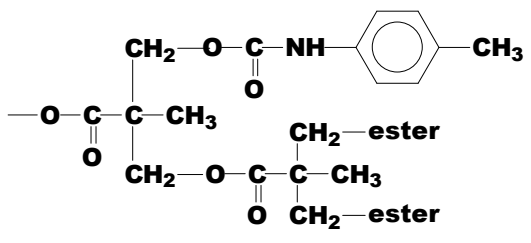

$$
\begin{aligned}
& \mathrm{D}_{1 \mathrm{u}}
\end{aligned}
$$

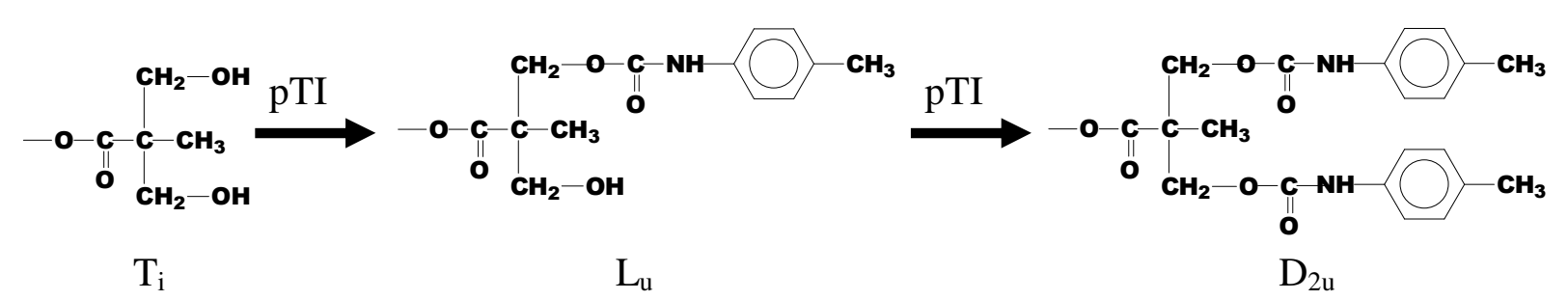


Figure 8

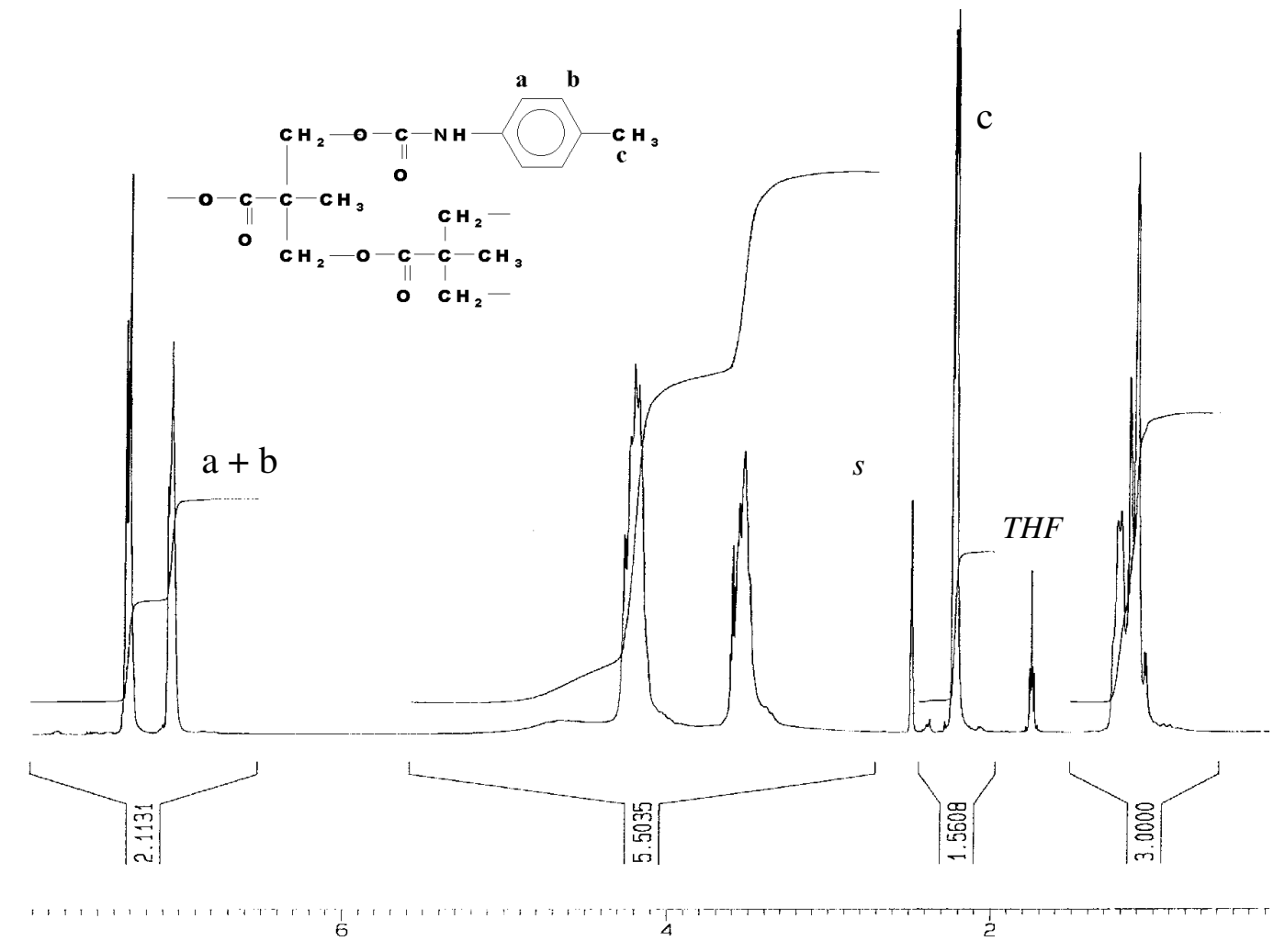

$\delta(\mathbf{p p m})$ 
Figure 9

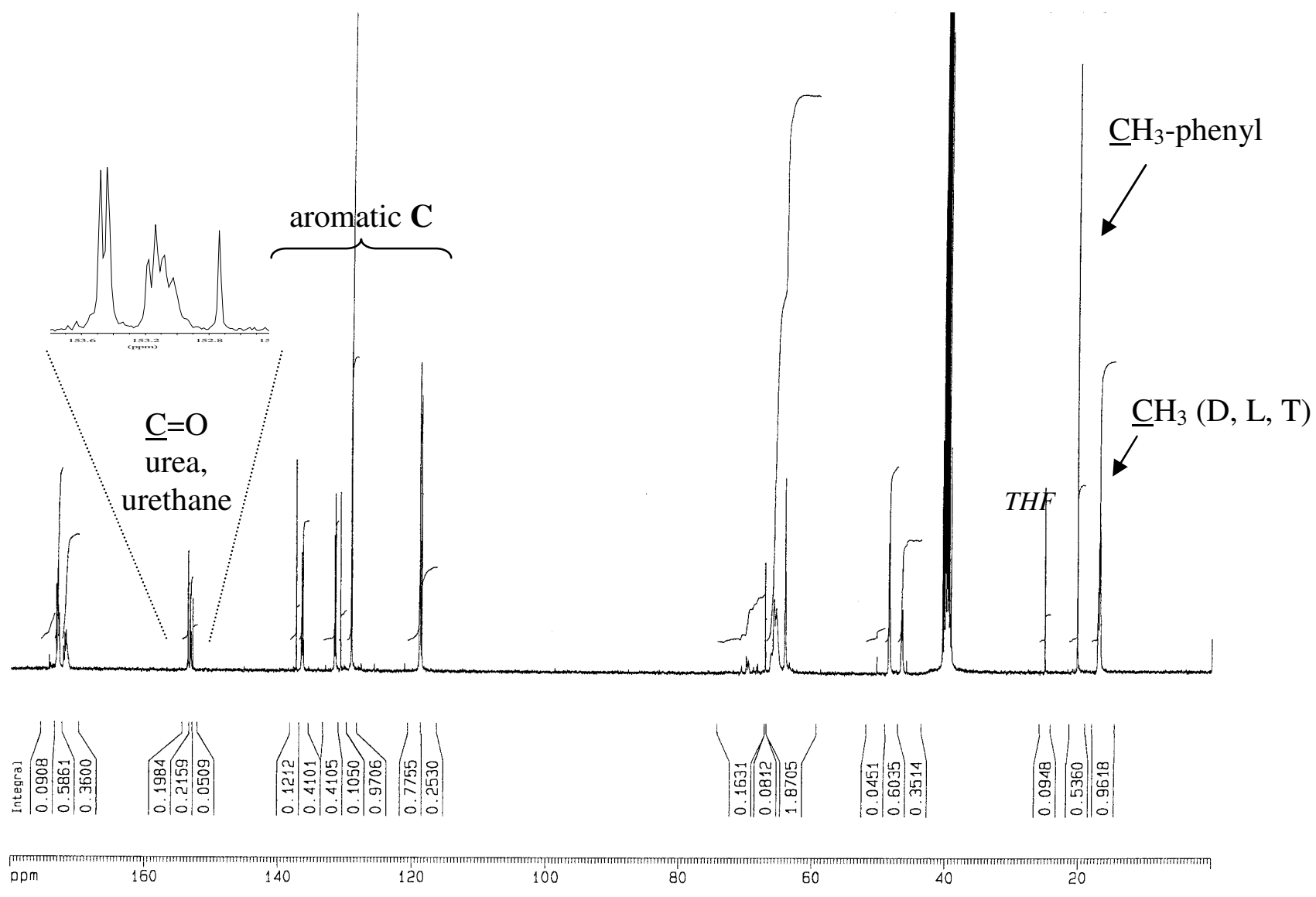


Figure 10

D
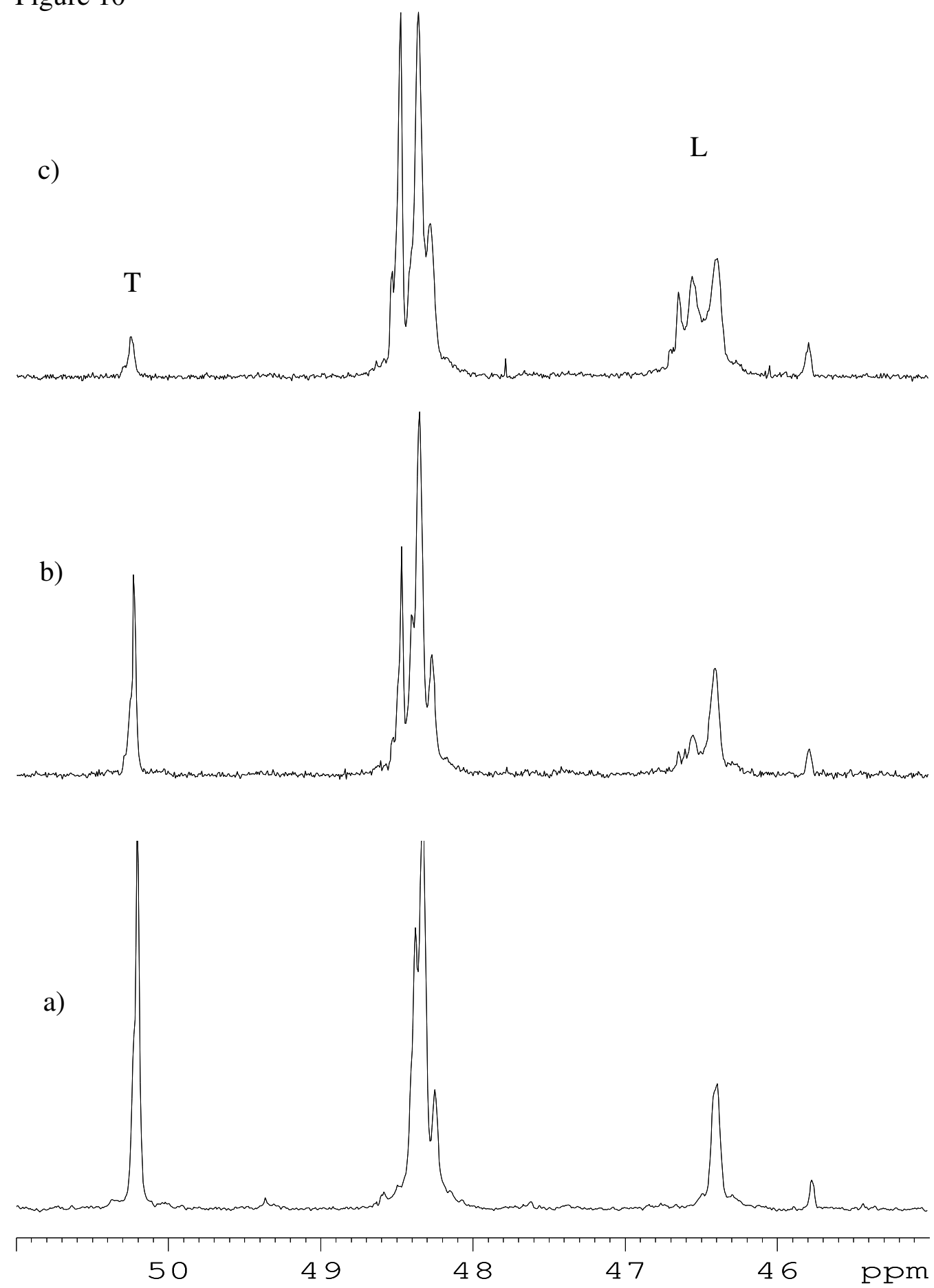
Figure 11

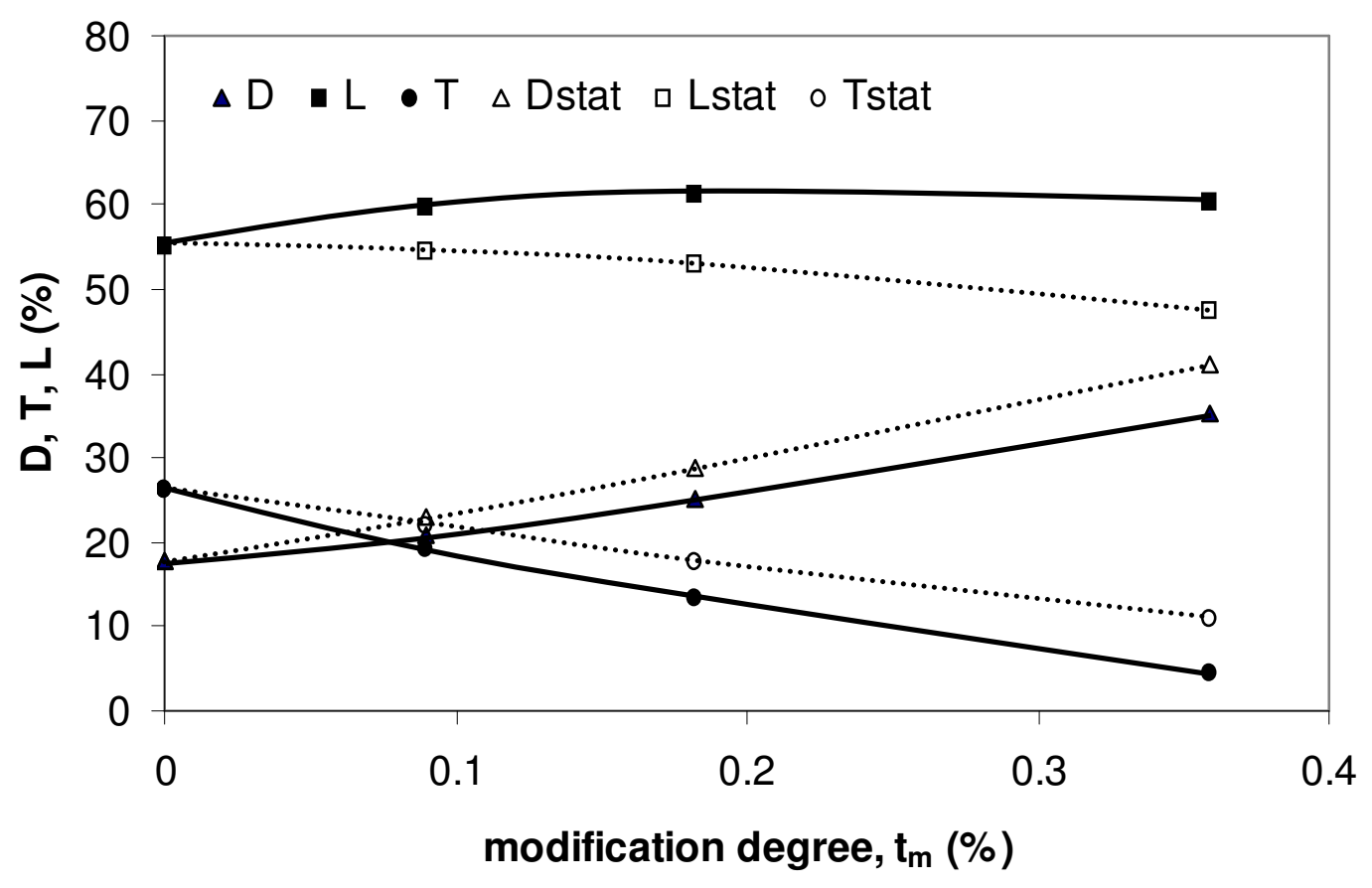


Figure 12
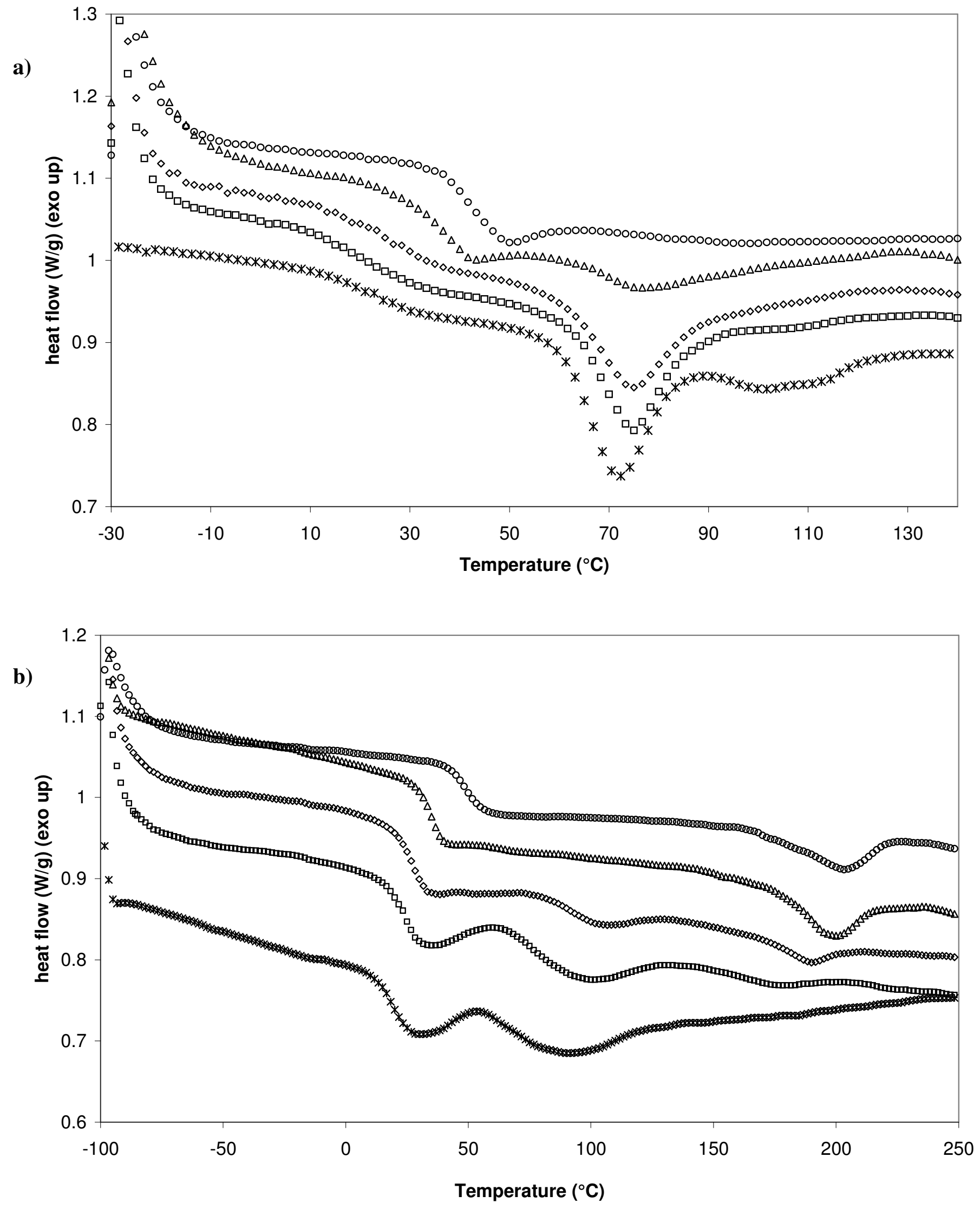
Figure 13

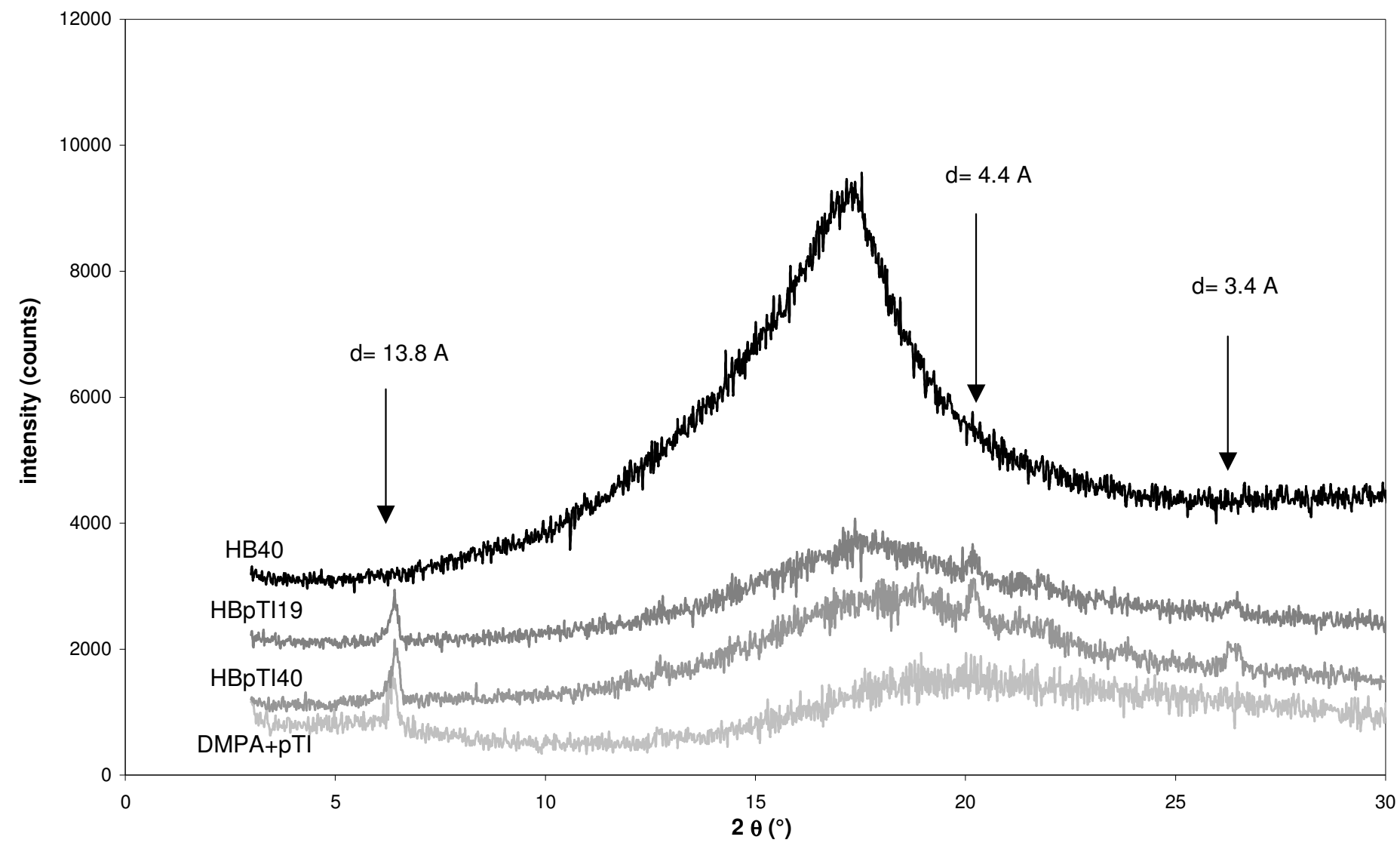


Figure 14

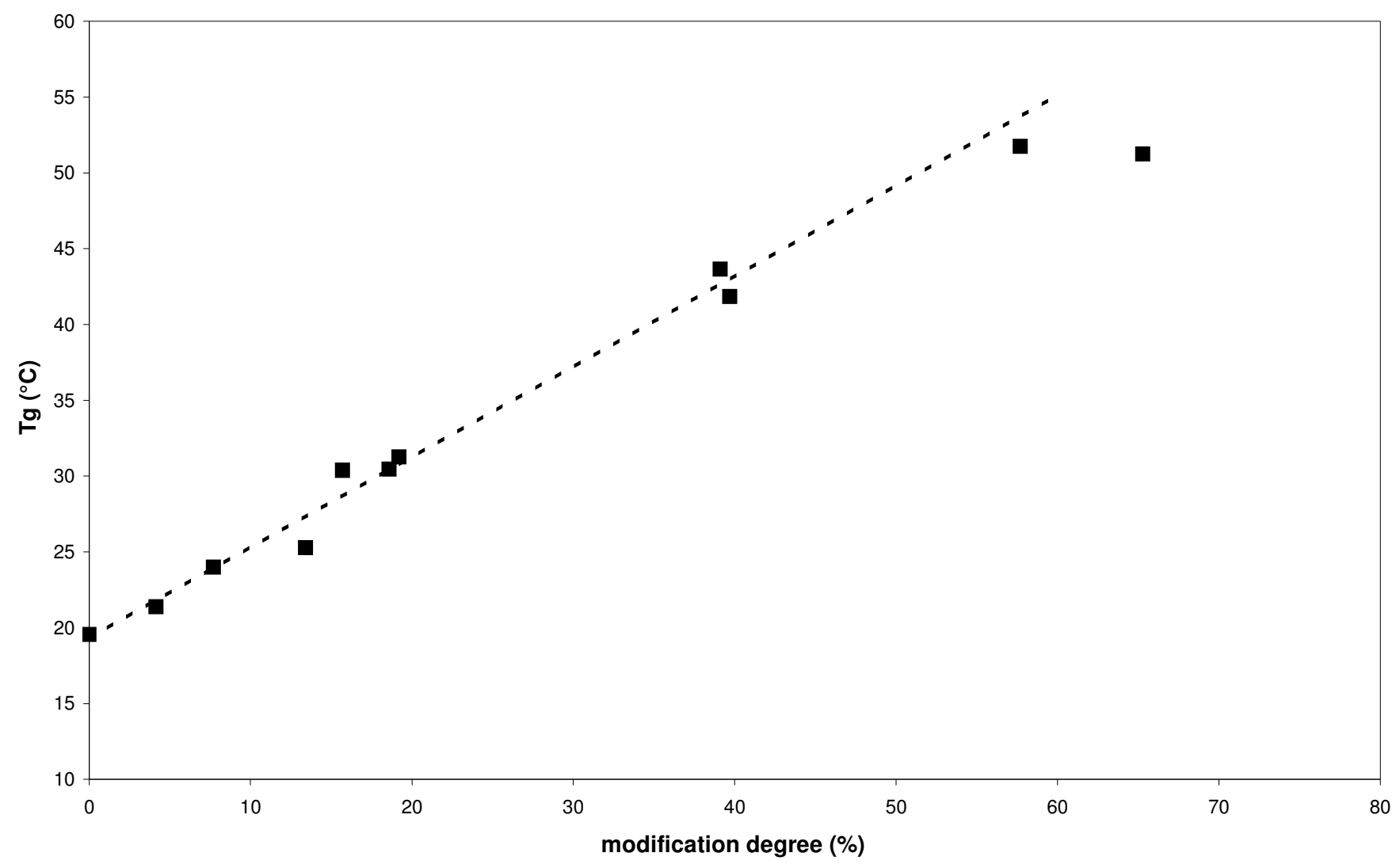


Figure 15

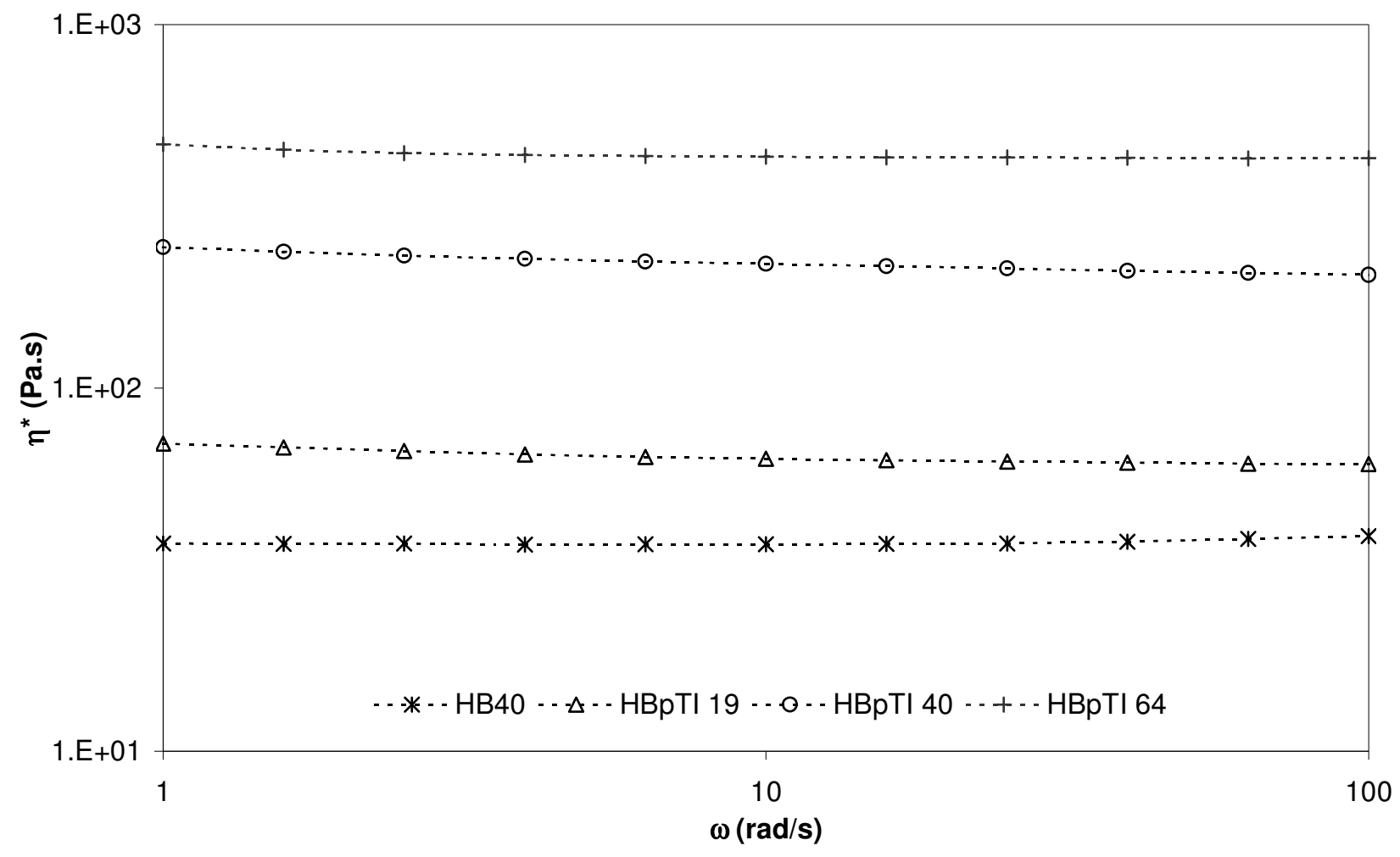


Figure 16

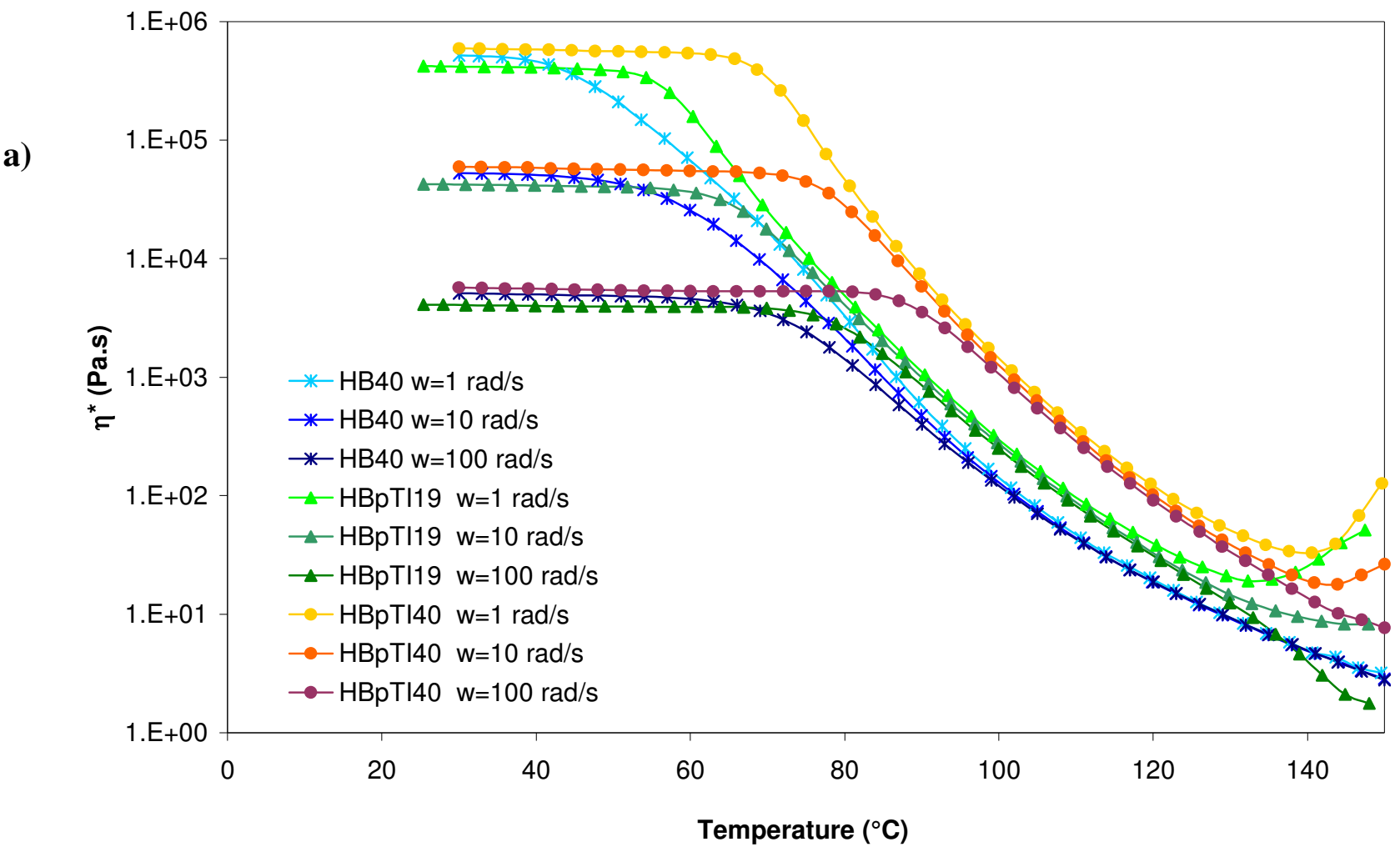

b)

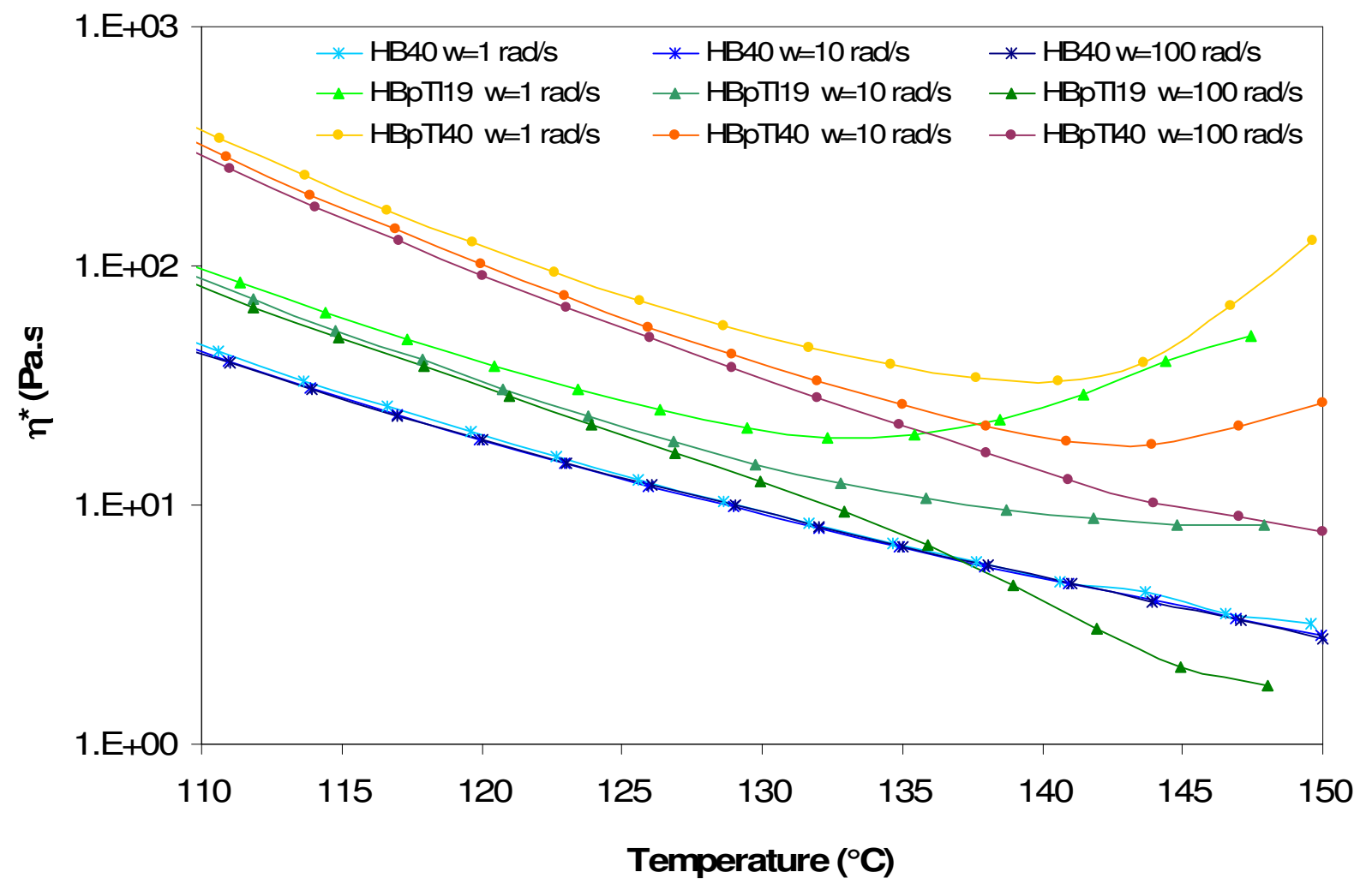


Figure 17

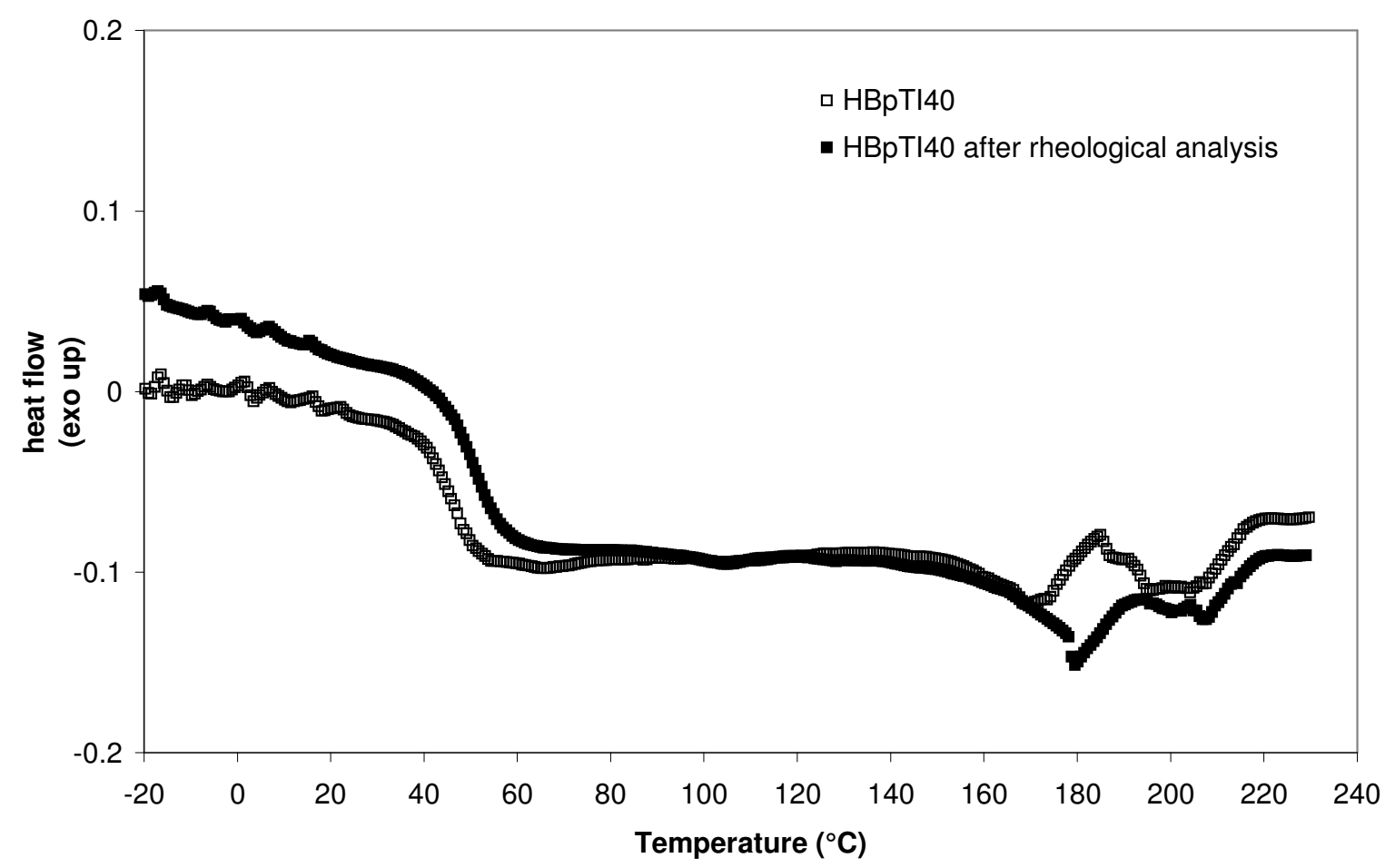

